\title{
Secondcoordination sphere effects on selectivity and specificity of heme and nonheme iron enzymes
}

DOI:

10.1002/chem.201905119

\section{Document Version}

Accepted author manuscript

Link to publication record in Manchester Research Explorer

\section{Citation for published version (APA):}

De Visser, S. (2019). Secondcoordination sphere effects on selectivity and specificity of heme and nonheme iron enzymes. Chemistry - A European Journal. https://doi.org/10.1002/chem.201905119

\section{Published in:}

Chemistry - A European Journal

\section{Citing this paper}

Please note that where the full-text provided on Manchester Research Explorer is the Author Accepted Manuscript or Proof version this may differ from the final Published version. If citing, it is advised that you check and use the publisher's definitive version.

\section{General rights}

Copyright and moral rights for the publications made accessible in the Research Explorer are retained by the authors and/or other copyright owners and it is a condition of accessing publications that users recognise and abide by the legal requirements associated with these rights.

\section{Takedown policy}

If you believe that this document breaches copyright please refer to the University of Manchester's Takedown Procedures [http://man.ac.uk/04Y6Bo] or contact uml.scholarlycommunications@manchester.ac.uk providing relevant details, so we can investigate your claim.

\section{OPEN ACCESS}


Second-coordination sphere effects on selectivity and specificity of heme and nonheme iron enzymes

Sam P. de Visser, ${ }^{*[a]}$

\section{substrate positioning}

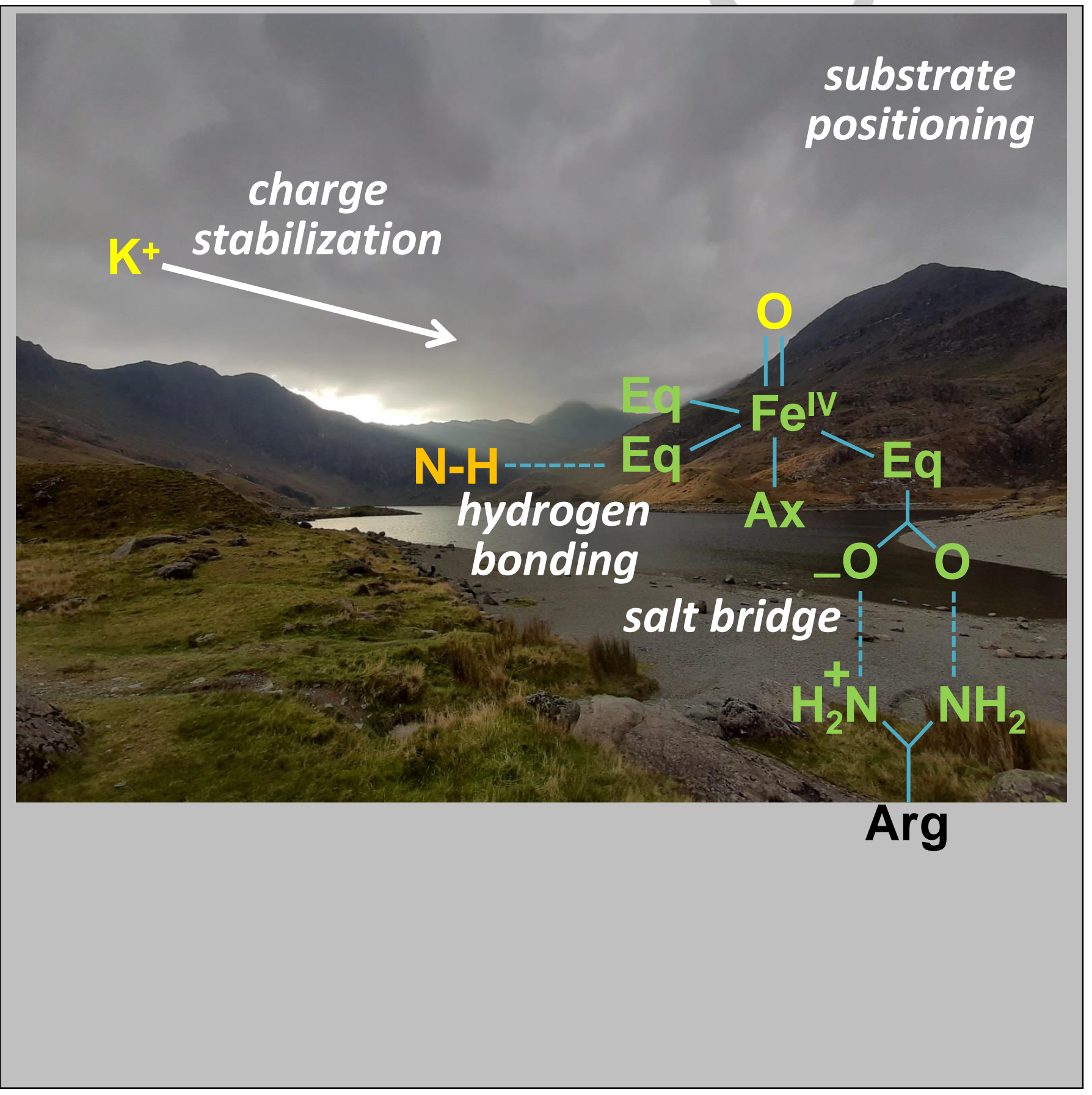


Abstract: Mononuclear iron containing enzymes are highly versatile oxidants that often react stereospecifically and/or regioselectively with substrates. Combined experimental and computational studies on heme monoxygenases, nonheme iron dioxygenases and halogenases have revealed the intricate details of the second-coordination sphere that determine this specificity and selectivity. These second-coordination sphere effects originate from the positioning of the substrate and oxidant, which involve the binding of the co-factors and substrate into the active site of the protein. In addition, some enzymes affect the selectivity and reactivity through charge-stabilization from nearby bound cations/anions, an induced electric field or through the positioning of salt-bridges and hydrogen bonding interactions to first-coordination sphere iron ligands and/or the substrate. Examples of all of these second-coordination sphere effects in iron-containing enzymes and how these influence structure and reactivity are given.

Biographical Sketch: de Visser is a computational chemist with more than 20 years' experience in modelling enzymatic reaction mechanisms with particular interest in the cytochromes P450 and nonheme iron dioxygenases. He obtained his degrees from the University of Amsterdam (the Netherlands) and gained postdoctoral experience at King's College London and the Hebrew University of Jerusalem. Since 2004 he has been a lecturer at the University of Manchester, where he currently has the rank of Reader. Over the years de Visser published more than 225 publications including 28 in Chemistry $-a$ European Journal.

\section{Introduction}

Enzymes are naturally occurring catalysts and are operating in all forms of life. Some enzymes are highly versatile and are able to activate a broad substrate scope, whereas others are highly selective and specific and produce a narrow range of products. For instance, the cytochrome P450 isozymes in the liver are tasked with detoxification processes in the body and hence target a broad substrate base. ${ }^{[1]}$ Indeed, the liver P450 isozymes activate many xenobiotics, although each isozyme has a different substrate scope and activity. On the other hand, biosynthesis reactions of hormones or natural products by the same class of enzymes require high specificity and often even enantioselectivity.

[a] Dr. S. P. de Visser

The Manchester Institute of Biotechnology and Department of Chemical Engineering and Analytical Science,

The University of Manchester, 131 Princess Street, Manchester M1

7DN, United Kingdom

E-mail: sam.devisser@manchester.ac.uk
To accommodate this, the P450s have a broad set of isozymes; all with the same heme active site, but with strong differences in the size and shape of the substrate binding pocket and local environment of the co-factor. Thus, some isozymes tightly bind and position the substrate and oxidant and force a regioselective reaction to happen. However, minor perturbations and manipulations to the substrate binding pocket and/or the catalysts positioning affects the reaction outcomes. How these seemingly small perturbations influence the structure and reactivity of enzymes is the focus of my review paper. In particular, the review will focus on the second-coordination sphere effects in ironcontaining enzymes and how it influences the structure, chemical properties and reactivity of its active site.

Among the mononuclear iron-containing enzymes, which we will discuss here, are important classes of monoxygenases and dioxygenases with a range of functions in all forms of life. Thus, the cytochromes P450 are heme-based monoxygenases that detoxify the body in the liver by initiating the metabolism of drugs and xenobiotics. ${ }^{[2]}$ These liver enzymes tend to be highly versatile and activate a range of substrates as expected from their biological function, although different P450 isozymes often give different product distributions and sometimes show low specificity. Other P450 isozymes have specific functions in biosystems; for instance, for the biosynthesis of hormones and natural products, ${ }^{[3]}$ and hence are highly selective and specific and work on a narrow substrate scope. Closely related to the P450s are the nitric oxide synthases (NOS), which are heme monoxygenases like the $\mathrm{P} 450$ s but are highly substrate selective and only bind an arginine residue into the substrate binding pocket. It is tightly bound and is converted into L-citrulline and NO, an important messenger molecule involved in blood pressure control and defense mechanisms. ${ }^{[4]}$

On the other hand, the body has a range of nonheme iron dioxygenases for biosynthesis, biodegradation and repair functions ${ }^{[5]}$ and although some of those enzymes can activate the same substrates as the cytochromes P450, they have different functions in biosystems that are not clearly understood. Within the mononuclear nonheme iron dioxygenases is a large class that is $\alpha$-ketoglutarate dependent, which in many cases react with substrates stereo- and regioselectively. Often these substrate selectivities and specificities originate from differences in the second-coordination sphere of enzyme active sites. In recent years many insights have been obtained from studies of ironcontaining enzymes into the function and nature of second coordination sphere effects in catalysis and how it guides the selectivity of the reaction.

Let me start this review with some general definitions of secondcoordination sphere effects (sometimes called non-covalent interactions $\left.{ }^{[6]}\right)$. The first- and second-coordination sphere perturbations on an iron center are described as shown in Scheme 1. The first coordination sphere of iron-ligands are the covalently bound residues in either the equatorial (Eq), axial (Ax) and distal (occupied by an oxo group in Scheme 1) positions. The first-coordination sphere ligands form bonding and antibonding orbitals with the metal, and, of course, the number of ligands, their bonding atom (nitrogen/oxygen/sulfur), the metal oxidation state as well as the overall symmetry (5-coordination versus 6coordination) determines the splitting of the metal 3d-orbitals, and hence affects the orbital occupation and the spin-state ordering. It has been shown that minor perturbations to the first-coordinate 
environment influences spin-state ordering and reactivities strongly. ${ }^{[7]}$

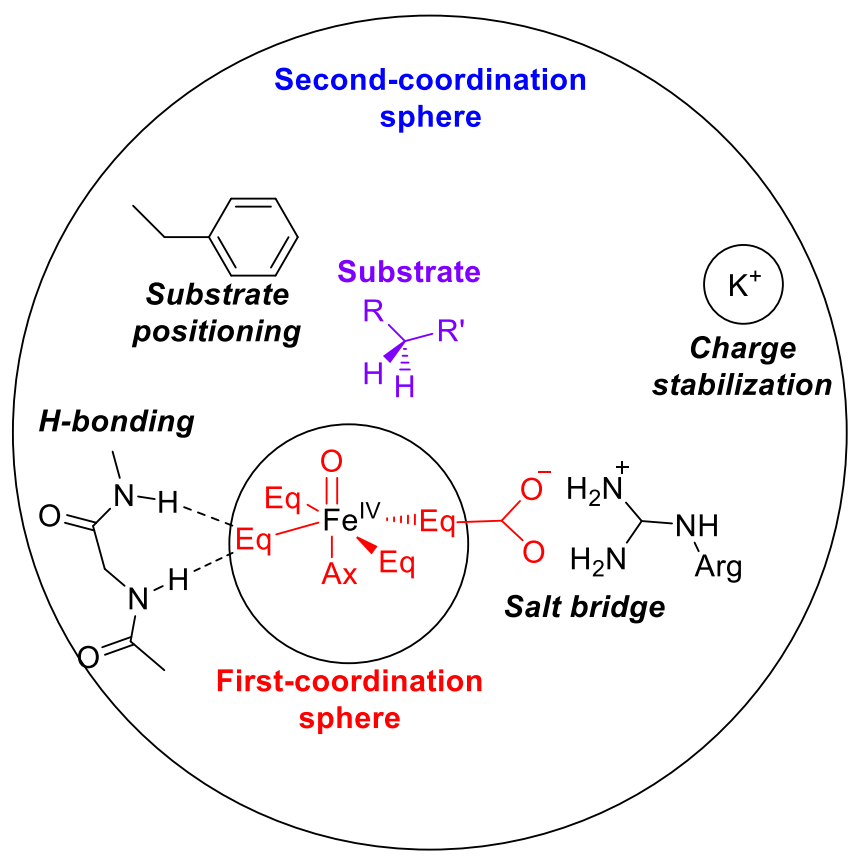

Scheme 1. Definition of the first- and second-coordination sphere in enzymes and the second-coordination sphere perturbations.

The second-coordination sphere of the metal environment contains residues that have atoms, which do not directly bind to the metal, but can affect its electronic properties through longrange interactions. These long-range interactions are highlighted in Scheme 1 and can range from ( $i$ ) charge-stabilization of a nearby cation or anion binding site, as exemplified with a $\mathrm{K}^{+}$ion, (ii) hydrogen bonding interactions to substrate or first-coordination sphere ligands from e.g. the protein backbone or polar amino acid residues, (iii) a salt bridge to first-coordination sphere ligands or substrate that positions the ligand, (iv) substrate positioning by the protein and local environment inside the substrate binding pocket. As such, the second-coordination sphere can influence local charge distributions as well as the electronic configuration of the oxidant and its molecular orbitals. Therefore, electronic perturbations through long-range effects can determine and change the redox potential of the metal, the $\mathrm{pK}_{\mathrm{a}}$ value of acidic and basic residues and other thermochemical properties that control the catalytic potential of the oxidant. Alternatively, substrate positioning in the active site brings the desired reaction site closest to the oxidant, while stereochemical clashes prevent alternative substrate sites from being activated. For example, a cation binding site from a bound $\mathrm{K}^{+}$ion in the vicinity of the active site can change the thermochemical properties and electronic configuration of the oxidant through long-range charge stabilization as will be explained below for cytochrome $c$ peroxidase. As shown below, in cytochrome $c$ peroxidase a local cation binding site changes the electronic configuration of the active species with respect to that of other peroxidases.
First-coordination sphere ligands, such as $\alpha$-ketoglutarate or succinate in nonheme iron enzymes, have a dangling carboxylate group that usually forms a salt bridge with an arginine (or lysine) residue of the peptide chain, which positions it in a specific orientation. The position of this arginine affects the reactivity of the iron(III)-superoxo with $\alpha$-ketoglutarate as shown in the ethylene forming enzyme (section 3.2). Other hydrogen bonding interactions to either substrate or first-coordination sphere residues can come from polar amino acid residues, water molecules or protein backbone groups. Again these small perturbations affect redox potentials and $\mathrm{pK}_{\mathrm{a}}$ values and determine the activity of the oxidant. Finally, substrate is often positioned tightly through either a network of hydrogen bonding interactions or through bulky/aromatic amino acid residues. In this review paper we will give an overview of these effects as seen in heme and nonheme iron enzymes as an example of secondcoordination sphere effects and focus on how these effects were shown to affect reactivity and selectivity.

\section{Second-coordination sphere effects in heme enzymes}

Heme enzymes have been extensively studied for decades and particularly the P450s of which many different isozymes have been discovered and characterized over the years. ${ }^{[1]}$ Their properties are determined by first- and second-coordination sphere effects as shown by many studies and as a consequence there are many different P450 isozymes with varying functions and properties. ${ }^{[8]}$ The first-coordination sphere of heme enzymes links the iron atom to the four nitrogen atoms of protoporphyrin IX in the equatorial positions. In addition, the iron binds an axial ligand that connects the heme to the protein. The distal ligand of iron represents the site for oxidant binding, i.e. water, dioxygen or $\mathrm{H}_{2} \mathrm{O}_{2}$. Typically, the cytochromes $\mathrm{P} 450$ have a cysteinate group as the axial ligand. ${ }^{[8 b, 9]}$ By contrast, heme peroxidases link the heme to the protein via a histidine group, while the catalases have a tyrosinate in that position. ${ }^{[10]}$ Nevertheless, all these heme enzymes pass through a catalytic cycle that forms a high-valent iron(IV)-oxo heme cation radical as active species, designated Compound I (Cpd I). It has been suggested that the anionic cysteinate ligand donates electron density to Cpd I through a "push"-effect that is essential to give it catalytic power. ${ }^{[11]}$ Indeed, the electron affinity (or redox potential) of Cpd I of P450 is considerably lower than that of, e.g., the analogous peroxidase Cpd I with a histidine axial ligand. ${ }^{[12]}$ This redox potential of Cpd I affects its catalytic potential as, e.g., in hydrogen atom abstraction processes, an electron is transferred to the heme. Indeed, a series of density functional calculations on models of P450 Cpd I and peroxidase $\mathrm{Cpd} I$ gave much lower reaction barriers for hydrogen atom abstraction and sulfoxidation reactions of substrates for the P450 system. ${ }^{[13]}$ Therefore, the firstcoordination sphere of ligands are important for the electronic properties of the oxidant and gives the oxidant catalytic power. In the next few sections, we will give examples of studies on heme systems where external perturbations through the secondcoordination sphere affected the structure and reactivity. 
(a)

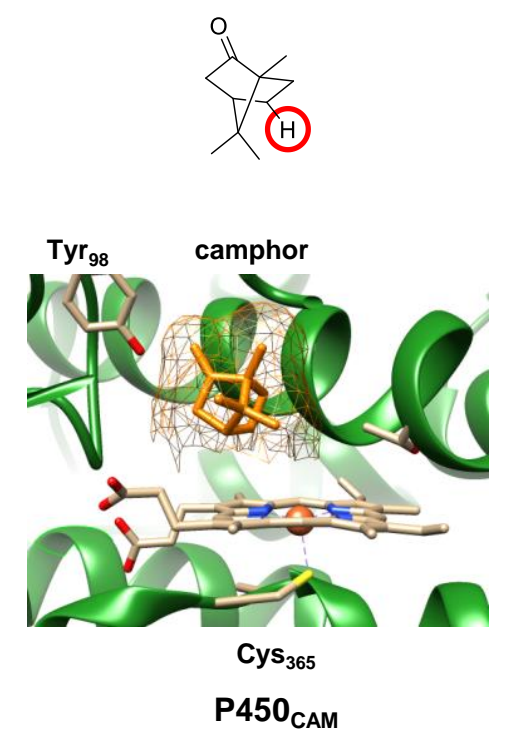

(b)

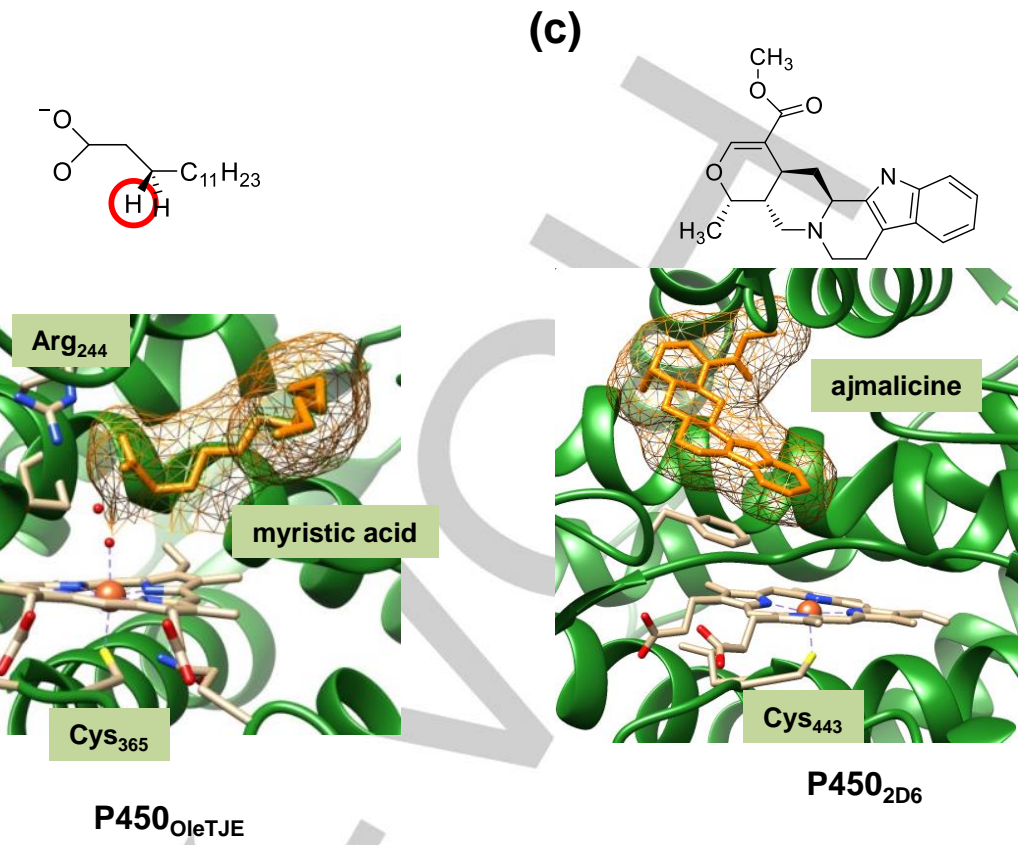

Figure 1. Substrate binding pockets as highlighted with a mesh around the substrate of (a) P450 CAM (3LXI pdb). (b) P450 OleTJE (6FYJ pdb). (c) P450 206 ( 4 WNT pdb). The hydrogen atom that is being activated by the enzyme is highlighted in the red circle in the chemical structure.

\subsection{Substrate positioning in $\mathrm{P} 450$ isozymes}

The large plethora of heme and nonheme iron dioxygenases and monoxygenases have differences in structure and function. For instance, among the cytochrome P450 isozymes (the P450s) there are isozymes with large substrate binding pockets, such as $\mathrm{P} 450_{2 \mathrm{D} 6},{ }^{[14]}$ while the isozyme P450 CAm is selective to camphor and regio- and stereospecifically hydroxylates it at the $\mathrm{C}^{5}$ position. ${ }^{[15]}$ Figure 1 displays the active site pockets of three typical P450 isozymes as taken from the Protein Data Bank. ${ }^{[16-19]}$ P450 CAM has a tight substrate binding pocket, whereby the $C^{5}$ position of substrate points toward the heme. It is believed this is guided through a hydrogen bond of $\mathrm{Tyr}_{98}$ to the keto-group of camphor that orients the substrate. ${ }^{[20]}$ Indeed, when De Voss et al. ${ }^{[20]}$ used thiocamphor as a substrate in P450 ${ }_{\text {CAm }}$ the selectivity was changed and little $C^{5}$-hydroxylation was observed but instead sulfoxidation products were detected. The P450 CAM substrate binding pocket is aligned with aliphatic residues, e.g. $\mathrm{Il}_{88}, \mathrm{Leu}_{252}$, $\mathrm{Leu}_{255}, \mathrm{Il}_{403}$ and $\mathrm{Val}_{404}$ that restrict the pocket to binding camphor and position it for chemoselective $\mathrm{C}^{5}$-hydroxylation. Poulos et al., showed that mutations in P450 СAM around the substrate binding pocket affected the spin-state ordering of the resting state and the ability to accept electrons from the redox partner and consequently did not activate substrate efficiently. ${ }^{[21]}$

By contrast to $\mathrm{P} 450_{\text {CAM }}$, the $\mathrm{P} 450_{2 \mathrm{D} 6}$ structure (panel $\mathrm{C}$ in Figure 1) binds a large substrate with five conjugated rings, namely ajmalicine, in the substrate binding pocket. This is not the sole substrate of the P450 isozyme as it is known to bind a large group of substrates with different shapes and sizes. ${ }^{[2,12]}$ Consequently, the $\mathrm{P}_{450_{2} 6}$ substrate binding pocket is much larger than that of P450 CAM, which does not fit ajmalicine, and can activate many substrate types and sizes. As $\mathrm{P}^{4} \mathrm{O}_{2 \mathrm{D} 6}$ is active in the liver with functions related to defense and detoxification of drug molecules and metabolites it is important that many substrates can be activated. The drug metabolizing P450 isozyme 3A4 in the liver is known to activate hundreds of different metabolites and hence has a relatively large substrate binding pocket that can accommodate substrates with varying shapes and sizes. ${ }^{[2,14]}$ For instance, with theobromine as a substrate the wildtype structure gives $19 \% \quad C^{5}$-hydroxylation and $81 \% \quad C^{4}$-hydroxylation as products. However, studies with the Ala370lle or Ala370Leu variants gave a regioselectivity reversal and produced dominant $\mathrm{C}^{5}$-hydroxylation instead. ${ }^{[22]}$ Similarly, with triple or quintuple mutants of P450 3A4 the activation of progesterone gave dominant $2 \beta$-hydroxylation rather than $6 \beta$-hydroxylation and, hence affected substrate positioning and activation. ${ }^{[21,23]}$

The substrate binding pocket of the $\mathrm{P} 450$ peroxygenase Ole $\mathrm{T}_{\mathrm{JE}}$ is shown in panel (b) of Figure 1. This enzyme utilizes $\mathrm{H}_{2} \mathrm{O}_{2}$ on an iron-heme active center and reacts through decarboxylation of fatty acids to terminal olefins by hydrogen atom abstraction from the $\beta$-position as main product channel. ${ }^{[24]}$ However, sideproducts are also observed leading to $\alpha-, \beta$ - and $\gamma$-hydroxylation as well as desaturation reactions. ${ }^{[25]}$ As can be seen from Figure 1 (b) the substrate binding pocket is long and thin and therefore accommodates linear long-chain fatty acids well. In addition, an active site Arg residue $\left(\operatorname{Arg}_{244}\right)$ forms a salt-bridge with the carboxylic acid head of the fatty acid and positions it into the active site. Thus, with linear long-chain fatty acids $\left(\mathrm{C}_{12}\right.$ and longer $)$ as substrates the major products obtained were through decarboxylation with a minor amount of $\beta$-hydroxylation. ${ }^{[24]}$ By contrast, using 2-phenyl propionic acid as a substrate mainly $\alpha$ hydroxylation with a minor amount of decarboxylation was observed. 
(a)

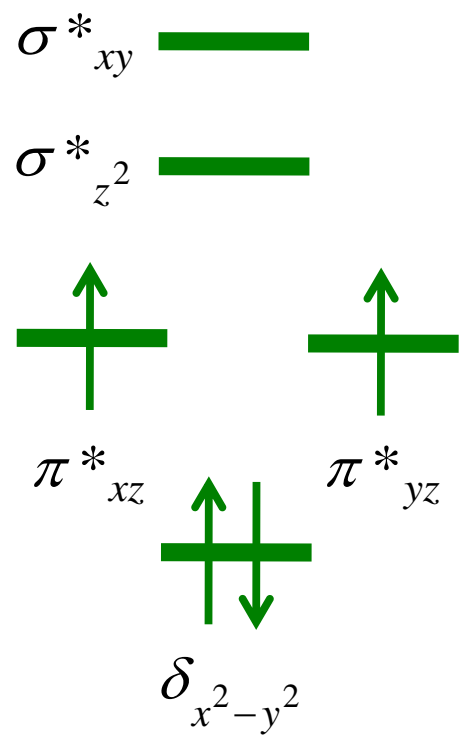

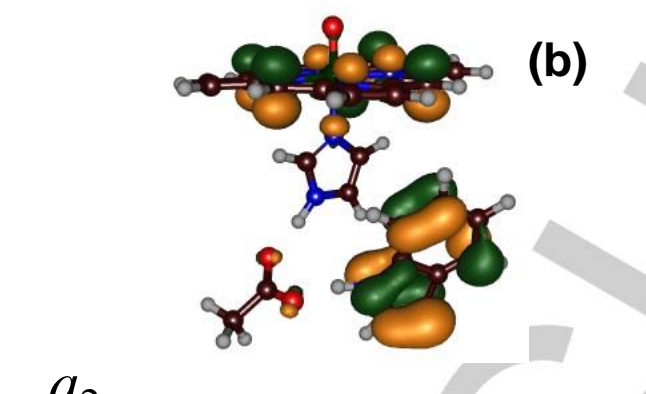
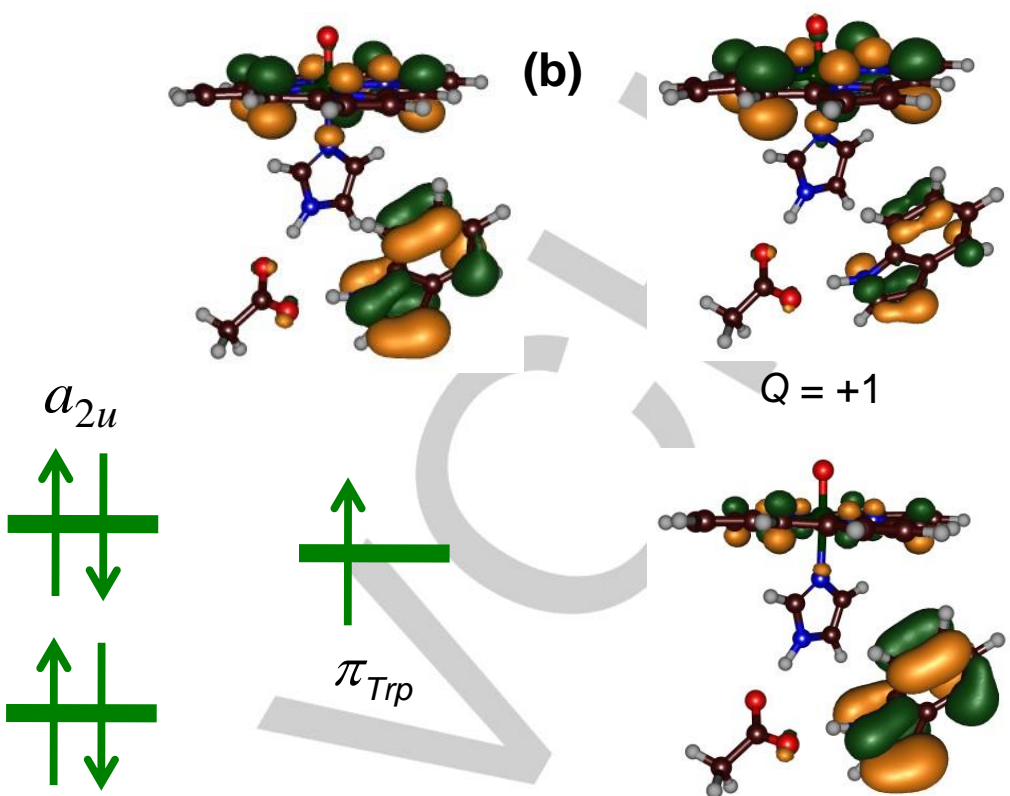

$a_{1 u}$
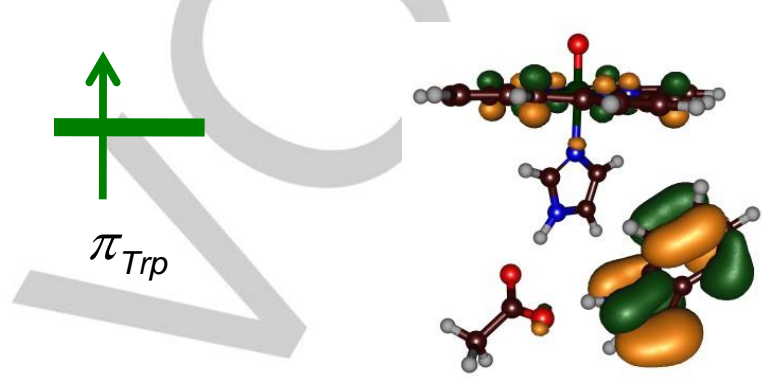

$Q=-1$

Figure 2. (a) Molecular orbitals of $\mathrm{C} c \mathrm{P} \mathrm{Cpd} I$ and orbital occupation. (b) Second-coordination sphere effects on the $\pi_{\mathrm{Trp}}$ orbital of $\mathrm{C} c \mathrm{P} \mathrm{Cpd} \mathrm{I}$ through the addition of a point charge with magnitude $Q= \pm 1$ at a distance of $12 \AA$ from iron.

Finally, 2-butyric acid as a substrate was activated by P450 OleT $_{J E}$ to form $\alpha$-hydroxylated and desaturated products mainly. ${ }^{[25]}$ These differences in product distributions were assigned to as the substrate binding pocket that affected the positioning of the substrate and hence its reactivity. Clearly, the second-coordination sphere of the protein has an important effect on catalysis; moreover, it can guide a stereo- and regioselective reaction mechanism that is unique to enzymes.

\subsection{Charge stabilization in heme enzymes}

One of the first peroxidases of which Cpd I was trapped and characterized with electron paramagnetic resonance (EPR) studies was cytochrome $c$ peroxidase $(\mathrm{CcP}){ }^{[26]} \mathrm{CcP}$ is a peroxidase involved in through-membrane electron transport processes in bacteria. ${ }^{[27]}$ Its electronic structure was long thought to be typical for heme Cpd I structures; however, further research on analogous peroxidases showed $\mathrm{C} C \mathrm{P}$ to have a unique chemical configuration. To explain the differences in molecular orbitals between P450 Cpd I and CcP Cpd I, we display in Figure 2 the high-lying occupied and low-lying virtual molecular orbitals of $\mathrm{C} c \mathrm{P} \mathrm{Cpd} \mathrm{I}$ as based on actives site model calculations reported previously. ${ }^{[28]}$ The orbitals shown in Figure 2 contain five orbitals that have a large metal $3 d$ contribution, namely $\delta_{x 2-y 2}, \pi_{x z}^{*}, \pi^{*}{ }_{y z}$, $\sigma^{*}{ }_{z 2}$ and $\sigma_{x y}^{*}$, whereby the $z$-axis is defined as passing through the $\mathrm{O}-\mathrm{Fe}-\mathrm{Ax}$ axis with $\mathrm{Ax}$ the axial ligand, while the $\mathrm{x}$ - and $\mathrm{y}$-axis pass through one of the $\mathrm{Fe}-\mathrm{N}_{\text {eq }}$ bonds of the heme. As the $\delta_{\mathrm{x} 2-\mathrm{y} 2}$ orbital is located in the plane of the heme with lobes bisecting the $\mathrm{Fe}-\mathrm{N}$ interactions, it cannot form favorable interactions with the heme and hence is non-bonding and lowest in energy. The $\pi^{\star}{ }_{x z}$ and $\pi^{*}{ }_{y z}$ orbitals are part of two pairs of orbitals $\left(\pi_{x z} / \pi^{*} \times z\right.$ and $\left.\pi_{y z} / \pi^{*}{ }_{y z}\right)$ located along the Fe-O axis. In Cpd I both $\pi_{x z}^{*}$ and $\pi_{y z}^{*}$ is singly occupied and correspond to the antibonding orbitals between the $3 d_{x z} / 3 d_{y z}$ orbitals on iron with the $2 p_{x} / 2 p_{y}$ atomic orbital on oxo. The two $\sigma^{*}$ orbitals are virtual in $\mathrm{Cpd} \mathrm{I}$ and represent the antibonding $\sigma$-type interactions of the metal with the first-coordination sphere and are located either along the O-Feaxial ligand axis $\left(\sigma_{z 2}^{*}\right)$ or in the plane of the heme $\left(\sigma_{x y}^{*}\right)$. In addition to these metal-type orbitals there are two heme-based $\pi^{*}$ orbitals that in $\mathrm{D}_{4 \mathrm{~h}}$ symmetry bear the labels $\mathrm{a}_{1 \mathrm{u}}$ and $\mathrm{a}_{2 \mathrm{u}}$. Finally, a high-lying amino acid orbital, i.e. a $\pi^{*}$ on the distal Trp residue designated $\pi_{\mathrm{Trp}}$ completes the valence set of orbitals. In CcP Cpd I the $\pi_{\mathrm{Trp}}$ orbital is singly occupied so that the overall configuration is $\delta_{x 2-y 2}{ }^{2} \pi_{x z}^{*}{ }^{1} \pi_{y z}^{*}{ }^{1} a_{1 u^{2}} a_{2 u^{2}}{ }^{2} \pi_{T r p}{ }^{1}{ }^{128]}$ By contrast, in other peroxidases as well as in the $\mathrm{P} 450$ s no protein radical is present and a Cpd I configuration of $\delta_{x 2-y 2}{ }^{2} \pi^{*}{ }_{x z}{ }^{1} \pi^{*}{ }_{y z}{ }^{1} a_{1 u^{2}} a_{2 u}{ }^{1}$ is found. ${ }^{[29]}$ The calculations were confirmed by experimental EPR and Mössbauer measurements on P450 CAM that identified a heme radical in Cpd I. ${ }^{[0]}$ As the two unpaired electrons on the FeO group (in $\pi^{*}{ }_{x z}$ and $\pi^{*}{ }_{y z}$ ) interact little with the radical on Trp, these electrons can be ferromagnetically coupled into a quartet spin state or antiferromagnetically coupled in a doublet spin state. A direct consequence of the close-lying doublet and quartet spin states results in reactivity and reaction mechanisms on competing spin state surfaces, which has been termed multistate reactivity. ${ }^{[31]}$ Multi-spin state reactivities by Cpd I was also found for analogous heme enzymes where the catalytic cycle passes through a high-valent iron(IV)-oxo heme/protein radical including $\mathrm{P} 450$, catalase, $\mathrm{C} c \mathrm{P}$ and other peroxidases. ${ }^{[32]}$

Although, the electronic configuration of $\mathrm{CcP} C \mathrm{Cpd}$ I was established from EPR and ENDOR measurements, ${ }^{[26]}$ as a matter of fact it was not easy to reproduce the results computationally. 
Thus, early DFT studies of Siegbahn et al..[3] on an active site model of C $c P$ Cpd I gave only partial spin density on the Trp group $\left(\rho_{\text {Trp }}=0.47\right)$, while the rest was located on the porphyrin ring. The $\pi_{\text {Trp }}$ orbital in Figure 2(a) indeed gives occupation on the heme as well as the Trp unit and hence it is a mixed orbital. As such, the calculations predicted the $\mathrm{a}_{2 \mathrm{u}}$ and $\pi_{\mathrm{Trp}}$ to be close in energy and a mixed configuration was observed. Further studies on CcP Cpd I identified a cation binding site and either using a full quantum mechanics/molecular mechanics (QM/MM) approach or the addition of a point charge to the model led to the correct charge and spin distribution as predicted by experiment. ${ }^{[28,34]}$

The shape of the $\pi_{\text {Trp }}$ orbitals with a point charge added to the model at $12 \AA$ distance from the iron atom are shown in Figure 2(b). As can be seen a positive charge with magnitude $Q=+1$ at $12 \AA$ makes the Trp group lesser ionizable and its unpaired spin density is reduced. As a consequence, the mixed $\pi_{T r p}-a_{2 u}$ orbital that is found in the gas-phase is being polarized through a point charge in the second-coordination sphere. Thus, with a positive charge in the second-coordination sphere of CCP the axial Trp group returns to a closed-shell conformation and will be charge neutral. At the same time, the porphyrin ring is ionized and loses an electron from the $a_{2 u}$ orbital, which is now the dominant valence orbital. By contrast, a point charge in the reverse direction, i.e. $Q=-1$, moves electron density from the porphyrin to the Trp group as is seen from the unpaired orbital. Therefore, $\mathrm{CcP} C \mathrm{Pd} I$ has two close-lying valence bond states, namely [(heme $\left.\left.{ }^{+*}\right)(\operatorname{Trp})\right]$ and [(heme) $\left.\left(\operatorname{Trp}^{+*}\right)\right]$ with orbital occupation $\mathrm{a}_{2 u^{1}} \pi_{T r p}{ }^{2}$ and $\mathrm{a}_{2 u^{2}}{ }^{2} \pi_{\operatorname{Trp}}{ }^{1}$, respectively. These two electronic configurations are close in energy and minor perturbations from the second-coordination sphere can reverse their ordering. In particular, the secondcoordination sphere effect in $\mathrm{C} c \mathrm{P}$ was found to stabilize a Cpd I structure with significant radical on the distal site Trp residue, while in other peroxidases (like ascorbate peroxidase) a heme radical is found. Indeed, an analysis of the analogous ascorbate peroxidase enzyme, where this cation binding site was missing gave a considerably different EPR signal resembling a heme radical and no Trp radical. Using site-directed mutations in the axial hydrogen bonded triad system of $\mathrm{C} c \mathrm{P}$, where replacement of the Asp by Gln, it was found that the redox potential of the Trp residue and the electronic configuration of $\mathrm{Cpd}$ I had changed. ${ }^{[35]}$ Further computational studies with an electric field perturbation included in the model showed that a change in electronic configuration for $\mathrm{C} C \mathrm{P}$ Cpd I can also be achieved through the addition of an electric dipole field or via the addition of a point charge to the model. ${ }^{[28]}$ As a matter of fact, a different electronic configuration was found with an additional point charge with magnitude +1 as compared to a -1 charge.

Studies on the heme enzyme nitrophorin 2 under different $\mathrm{pH}$ conditions found $\mathrm{Cpd}$ I structures with a porphyrin radical at acidic $\mathrm{pH}$, while a Tyr radical was detected with EPR under basic conditions. ${ }^{[36]}$ These studies show that local $\mathrm{pH}$ and probably hydrogen bonding interactions from the second coordination sphere affect the structure and electronic configuration of $\mathrm{Cpd} \mathrm{I.}$

\subsection{Hydrogen bonding to first-coordination sphere ligands in the P450s}

The first-coordination sphere ligands in the P450s contain the heme, the axial cysteinate ligand and a variable distal ligand. The axial cysteinate is part of a small loop, where backbone amine groups hydrogen bond to the cysteinate ligand. ${ }^{[37]}$ Various studies have explored the effect of these hydrogen bonding interactions. Thus, Kincaid et al. ${ }^{[38]}$ and Davydov et al. ${ }^{[39]}$ showed that for the P450 2B4 isozyme an additional hydrogen bonding interaction changed the electronic configuration of resting state structure through more sulfur to iron charge donation, which affected spin state ordering as measured by changes in iron-sulfur frequencies with resonance Raman spectroscopy and EPR experiments. Calculations on active site models of P450 Cpd I with these hydrogen bonds to the thiolate axial ligand mimicked by two hydrogen bonded ammonia molecules showed differences in electronic configuration with considerable less spin density on sulfur and more on the heme. ${ }^{[40]}$ As such, models that included hydrogen bonding interactions to the thiolate had group spin densities that were closer to the expected ones based on EPR and Mössbauer spectroscopy experiments. ${ }^{[30]}$

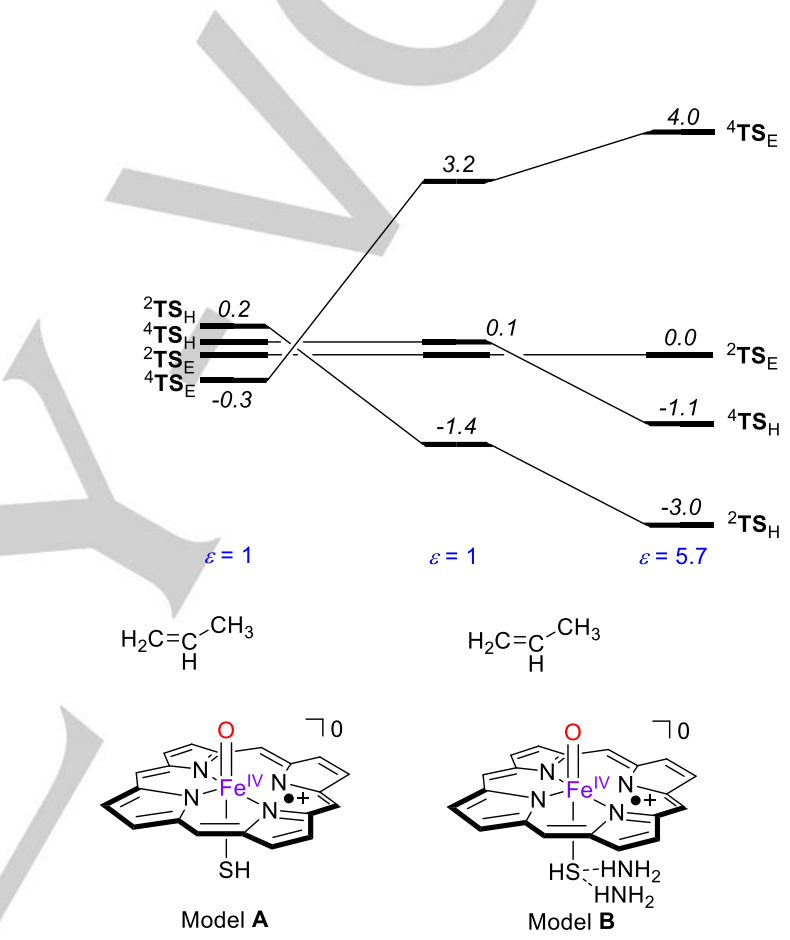

Figure 3. Propene epoxidation (via ${ }^{2,4} \mathbf{T} \mathbf{S}_{\mathrm{E}}$ ) and hydroxylation (via ${ }^{2,4} \mathbf{T} \mathbf{S}_{\mathrm{H}}$ ) as calculated with P450 model complexes. Energies are $\Delta \mathrm{E}+\mathrm{ZPE}$ values in kcal $\mathrm{mol}^{-1}$. Data from Ref ${ }^{[41 \mathrm{~b}]}$

These hydrogen bonding interactions to the thiolate axial ligand of P450 Cpd I were also found to change the redox potential of Cpd I and diminished its catalytic activity. Therefore, a series of studies were performed by investigating the bifurcation pathways to different reaction channels through environmental perturbations. As mentioned above some of the P450 isozymes react highly selectively with substrates even though many different reaction channels are possible under free movement and binding of the substrate. In general, the P450s react through oxygen atom transfer, which often results in hydroxylation of an aliphatic or aromatic $\mathrm{C}-\mathrm{H}$ bond, epoxidation of a $\mathrm{C}=\mathrm{C}$ double bond or sulfoxidation of sulfides. ${ }^{[1,2,31]}$ In addition, reaction channels through desaturation and demethylation have been observed. To understand the factors that determine these different reaction channels a number of computational studies were performed. 
One of the earliest computational studies on bifurcation pathways by the P450s was performed on propene as a substrate and investigated the $\mathrm{CH}_{3}$ hydroxylation versus $\mathrm{C}=\mathrm{C}$ epoxidation reactions using model complexes. ${ }^{[41]}$ In particular, the secondcoordination sphere effects on the chemoselectivity of propene epoxidation versus hydroxylation were explored and details are given in Figure $3 .{ }^{[41]}$ The initial studies were done with gas-phase density functional theory models and predicted (based on $\Delta \mathrm{E}+\mathrm{ZPE}$ energies, $\mathrm{ZPE}=$ zero-point energy) barriers within one $\mathrm{kcal} \mathrm{mol}^{-1}$ for epoxidation and hydroxylation on the doublet and quartet spin states. However, when the hydrogen bonding interactions toward the thiolate were taken into account in the model the pathway for doublet spin hydrogen atom abstraction was stabilized while the quartet spin epoxidation pathway was destabilized, so that the range of the four transition states expanded to $4.6 \mathrm{kcal} \mathrm{mol}^{-1}$. Further changes were seen when a polarized continuum model mimicking the protein environment was added to the system with a dielectric constant of $\varepsilon=5.7$. This model gave preferential hydroxylation via a doublet spin transition state $\left({ }^{2} \mathbf{T S}_{\mathrm{H}}\right)$ by $3 \mathrm{kcal} \mathrm{mol}^{-1}$ over epoxidation via a doublet spin transition state $\left({ }^{2} \mathbf{T} \mathbf{S}_{\mathrm{E}}\right)$ in agreement with experimental studies on propene activation by P450 enzymes. ${ }^{[42]}$ Subsequent studies of Mulholland et al. ${ }^{[43]}$ using the quantum mechanics/molecular mechanics (QM/MM) technique reproduced experimental product distributions of cyclohexene epoxidation versus hydroxylation and identified the second-coordination sphere effect of P450 enzymes that determined substrate positioning and selectivity.

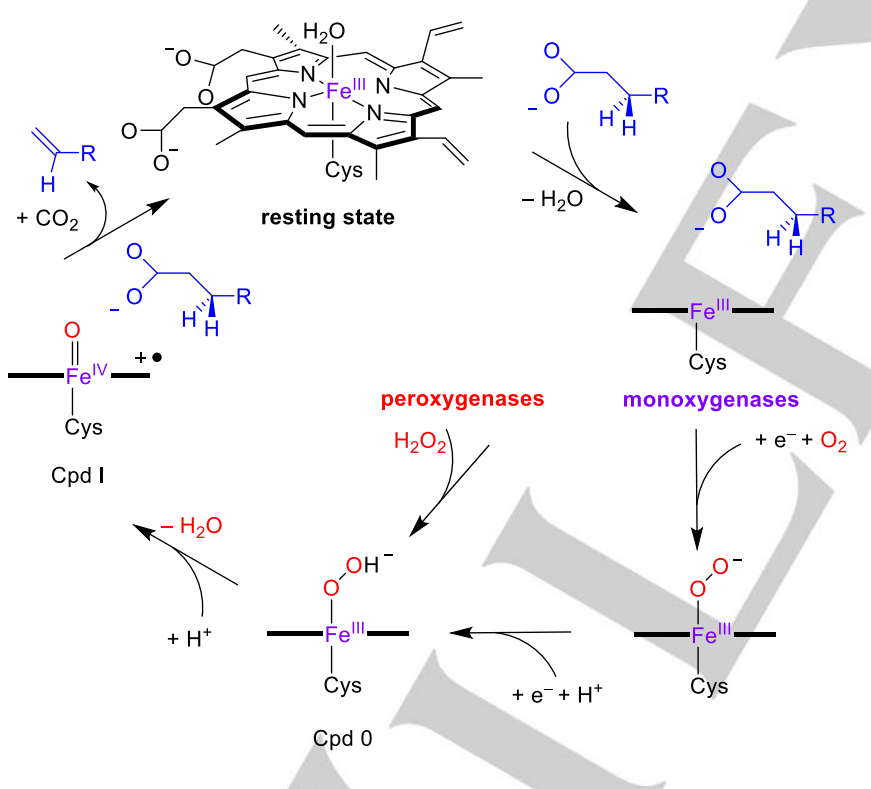

Scheme 2. Catalytic cycles of $P 450$ monoxygenase and $P 450$ peroxygenase enzymes.

Further studies using external electric fields applied along the molecular $x-, y$ - or $z$-axis of the heme showed that the chemoselectivity of propene epoxidation versus hydroxylation can also be reversed through an applied electric field along the molecular x-axis. ${ }^{[44]}$ Therefore, P450 selectivity and reactivity is subtly dependent on the local environment of the enzyme, the substrate and the heme groups. External influences, such as charged residues from the protein or an external electric field affect the charge distributions of the active oxidant and substrate and, thereby, can influence reactivity patterns and bifurcation pathways. These computational studies show that the P450s should give ample opportunity in biocatalysis for the design of biocatalytic reaction systems for selective activation of substrate.

\subsection{Substrate positioning in $\mathrm{P} 450$ OleT $\mathrm{JE}$}

As the P450s are highly versatile and selective and react with substrates efficiently, there have been efforts to utilize the P450s in biotechnology, for instance, for the biosynthesis of biofuels from fatty acids. Unfortunately, most P450s use molecular oxygen and bind a redox partner that delivers two electrons into the catalytic cycle, see Scheme 2. These redox partners make the P450s unsuitable for use in biotechnology as they are expensive. In recent years; however, a novel P450 isozyme was discovered that reacts with $\mathrm{H}_{2} \mathrm{O}_{2}$ rather than $\mathrm{O}_{2}$ and, therefore, acts as a peroxygenase. ${ }^{[25,45]}$

The catalytic cycles of $\mathrm{P} 450$ peroxygenases and monoxygenases are depicted in Scheme 2. Both start from an iron(III)-heme resting state, where water is bound in the distal position of iron. Upon substrate binding this water is expelled and either hydrogen peroxide binds (in peroxygenases) or the metal is reduced and binds molecular oxygen (in monoxygenases). Hydrogen peroxide binding enables a shunt-mechanism that directly forms the iron(III)-hydroperoxo intermediate (Compound 0, Cpd 0) through reshuttling of protons and without the need of external electrons and protons. ${ }^{[25]}$ By contrast, the monoxygenases require a redox partner to donate two electrons and two protons to pass to Cpd I in the catalytic cycle. ${ }^{[1,46]}$

The $\mathrm{P} 450$ peroxygenase $\mathrm{OleT}_{\mathrm{JE}}$ was found to bind long-chain fatty acids and react them to terminal olefins as a main product through a decarboxylation reaction. ${ }^{[45]}$ Unfortunately, the reaction mechanism of fatty acid activation by Ole $_{\mathrm{JE}}$ gives significant amount of by-products that are unwanted and hence work is ongoing to engineer these enzymes for optimal production of terminal olefins. To gain insight into the origins of the product distributions of branched and linear fatty acid activation by P450OleTJE, a combined experimental and computational study was performed. ${ }^{[25]}$ The experimentally measured product distributions for 2-methylbutyrate gave dominant $\alpha$-hydroxylation and $\alpha / \beta$-desaturation products, while no $\beta$-hydroxylation and decarboxylation was found. By contrast, long-chain fatty acids, such as myristic acid gave mostly decarboxylation and a minor amount of $\beta$-hydroxylation products and no $\alpha$-hydroxylation and desaturation. As such, the size and shape of the substrate and consequently its binding and positioning in the active site influences the product distributions in P450 OleT JE. 
(a)

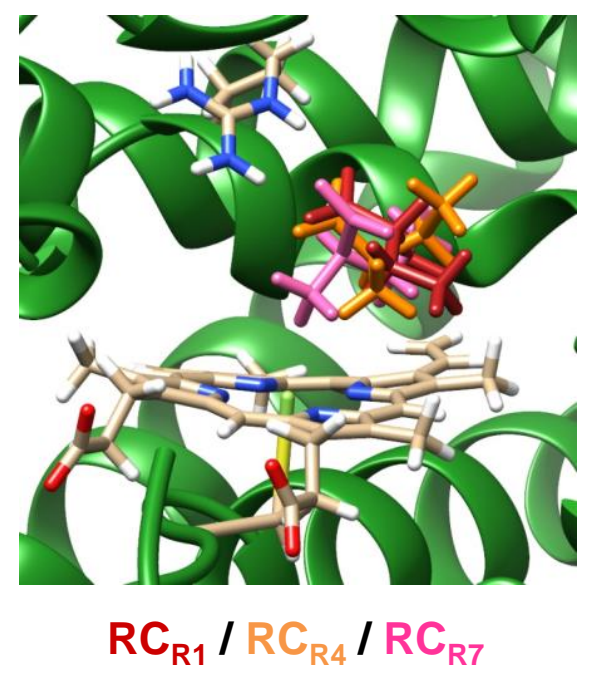

(b)

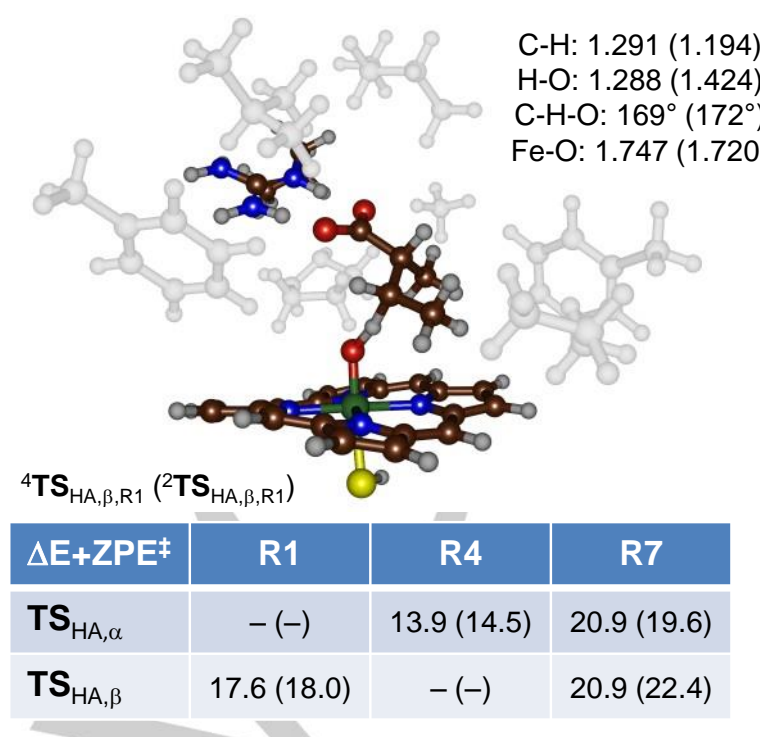

Figure 4. DFT calculated reaction mechanism of substrate activation by $\mathrm{P} 450$ OleT JE using (R)-2-methylbutyrate as substrate. (a) Overlay of three low-energy substrate binding positions R1, R4 and R7 in the reactant complex (RC). (b) Hydrogen atom abstraction barriers $\left(\Delta E_{+}+\mathrm{ZPE}\right.$ in kcal mol-1) calculated with DFT for $\alpha-$ and $\beta$-hydrogen atom abstraction by ${ }^{4,2} \mathrm{Cpd}$ I from $(R)$-2-methylbutyrate by a P450oleTJE Cpd I model complex. The structure of ${ }^{4,2} \mathbf{T S}_{\mathrm{HA}, \beta, \mathrm{R} 1}$ are shown with bond lengths in angstroms.

To understand the differences in product distributions, a set of computational studies were performed using either QM/MM on a full protein model or a large cluster model of the active site structure. ${ }^{[25,47]}$ The subsequent modelling started with docking of the substrate into the substrate binding pocket followed by a density functional theory (DFT) optimization of a 163 atom cluster model that includes the heme and the residues lining the substrate binding pocket.

All conformers were geometry optimized with DFT and their energetics and product distributions compared. For $(R)-2-$ methylbutyrate, three low-energy substrate-bound configurations were found, namely $R 1, R 4$ and $R 7$, whereby $R 1$ was found to be the most stable structure and therefore has the substrate the strongest bound. Thus, R1 and R4 form a strong salt-bridge with the active site $\operatorname{Arg}_{244}$ residue with both oxygen atoms of the carboxylate, whereas in R7 only one of those atoms points towards the salt bridge. Not surprising, R7 is less stable than R1 and $\mathrm{R} 4$ by about 7 and $5 \mathrm{kcal} \mathrm{mol}^{-1}$, respectively. For the $(S)$ enantiomer, the substrate binding revealed five stable conformations of (S)-2-methylbutyrate nearby a Cpd I structure with either one or two direct hydrogen bonds between substrate and active site $\operatorname{Arg}_{244}$ residue.

Subsequently, hydrogen atom abstraction from the $\alpha$ - and $\beta$ position of $(R)$ - and $(S)$-2-methylbutyrate by Cpd I was calculated. However, due to positioning of the substrate with respect to oxidant, not all of the positions were accessible for hydrogen atom abstraction as is shown for the $(R)$-enantiomer conformers as an example in the Table in Figure 4b. Thus, in position R1 the substrate is lined up for $\beta$-hydrogen atom abstraction and the modelling found $\beta$-hydroxylation to be the only viable pathway with the substrate in this orientation. In particular, the ethyl group of substrate points to $\mathrm{Cpd} \mathrm{I}$, whereas the methyl group points in the other direction. Furthermore, the $\alpha$-hydrogen atom points away from Cpd I and due to the rigidity of the salt bridge between $\operatorname{Arg}_{244}$ with the carboxylate group of substrate, Cpd I cannot access it properly. By contrast, with substrate in position R4 the substrate is located upside down in the substrate binding pocket with the $\alpha$-hydrogen atom in the vicinity of $\mathrm{Cpd} \mathrm{I} \mathrm{and} \mathrm{the} \mathrm{ethyl}$ group pointing to the back. As a result, in R4 the favorable pathway is $\alpha$-hydrogen atom abstraction and no feasible $\beta$ hydroxylation pathway could be identified. On the other hand, with the sideways oriented substrate R7 both $\alpha$ - and $\beta$-hydrogen atom abstraction positions are accessible to $\mathrm{Cpd} \mathrm{I}$, although all four barriers are well higher in energy than the barriers found from substrate binding position R4. The lowest energy barriers; therefore, are found for $\alpha$-hydrogen atom abstraction with substrate in the R4 position and, therefore, $\alpha$-hydrogen atom abstraction is expected to be dominant.

Further studies showed that decarboxylation and the formation of terminal olefins is only possible after an initial hydrogen atom abstraction from the $\beta$-position. ${ }^{[47]}$ This implies that no decarboxylation products will be obtained from $(R)$-2methylbutyrate activation by $\mathrm{P} 450 \mathrm{OleT}_{\mathrm{JE}}$ and the dominant products based on the computational modelling are expected to be $\alpha$-hydroxylation. These predictive results matched experimentally determined product distributions excellently. Consequently, substrate positioning in P450 OleTJE is important as it determines the site of activation of the substrate and hence the product distributions. A similar observation of effects of the second-coordination sphere on substrate binding was through experimental studies on P450 CAM mutants studied ethylmethylbenzene hydroxylation and found $(R)$-enantiomer products for some mutants and the $(S)$-enantiomer for other mutants. ${ }^{[48]}$ 


\section{Second-coordination sphere effects in nonheme iron enzymes}

Mononuclear nonheme iron dioxygenases are diverse enzymes in molecular biology and are found in most biosystems. ${ }^{[49]}$ They have functions in biology related to the synthesis of natural products, such as $(2 S, 4 R)$-4-hydroxyproline in humans, ${ }^{[50]}$ as well as biodegradation of toxic compounds that includes the catabolism of cysteine in the body. ${ }^{[51]}$ Nonheme iron dioxygenases often bind the substrate in a tight configuration; thereby reacting selectively with substrate for biosynthesis purposes of specific natural products, antibiotics and signaling molecules. Since they are highly diverse, they have been studied extensively using experimental as well as computational methods, but many questions remain as to how this selectivity is achieved and how alternative product channels are blocked.

Despite their differences in reactivity and chemical catalysis, often the first-coordination sphere of atoms surrounding the iron atom is the same. Thus, typically nonheme iron dioxygenases have a first-coordination sphere of iron ligands in a facial orientation with two histidine and one carboxylic acid (of Glu or Asp), whereby one of the histidine ligands occupies the axial position and the other histidine and the carboxylic acid two equatorial positions of the metal. ${ }^{[52]}$ In the resting state the remaining three first-coordination sphere sites of iron are occupied by water molecules (Scheme 3). The catalytic cycle starts when these water molecules are replaced by (co)-substrate and dioxygen, whereby dioxygen is proposed to bind trans to one of the histidine ligands, while the other sites bind co-substrate or substrate. Accordingly, in intradiol and extradiol catechol dioxygenases substrate binds as a bidentate ligand in the equatorial plane and dioxygen in the distal position, while the remaining ligands of iron are side chains of a glutamic acid and three histidine groups although sometimes a tyrosinate ligand is also included. ${ }^{[53]}$ In a similar vein, in the nonheme iron enzyme acireductone dioxygenase substrate binds the iron as a bidentate ligand in the equatorial plane and reacts with dioxygen directly on the iron center. ${ }^{[54]}$

Many nonheme iron dioxygenases utilize $\alpha$-ketoglutarate as a cosubstrate that in a reaction with the iron(III)-superoxo structure forms succinate and a high-valent iron(IV)-oxo species (Scheme $3)$. In nonheme iron/ $\alpha$-ketoglutarate dependent dioxygenases it is believed that $\alpha$-ketoglutarate binding precedes dioxygen binding in the catalytic cycle. ${ }^{[55]}$ The iron(IV)-oxo species is the active oxidant of the enzyme and generally reacts with aliphatic groups through hydrogen atom abstraction. It was characterized with spectroscopic methods for several nonheme iron/ $\alpha$-ketoglutarate dependent dioxygenases. ${ }^{[56]}$ In the nonheme iron halogenases a similar reaction takes place to form an iron(IV)-oxo active species from $\alpha$-ketoglutarate and dioxygen binding even though their ligand configuration is 2-His/1-X $\left(\mathrm{X}=\mathrm{Cl}^{-} / \mathrm{Br} / \mathrm{I}^{-}\right)$, where the equatorial Asp or Glu ligand is replaced by a halide. ${ }^{[57]}$ Most of these nonheme iron/ $\alpha$-ketoglutarate dependent dioxygenases are highly selective and react with high product specificity. For example, prolyl-4-hydroxylase is an $\alpha$-ketoglutarate dependent nonheme iron dioxygenase that catalysis the biosynthesis of $(2 S, 4 R)$-4-hydroxyproline from proline; an important component of collagen in the skin. ${ }^{[50]}$ Computational modelling showed that thermodynamically $\mathrm{C}^{5}$-hydroxylation of proline should be the energetically favorable pathway, yet this product is not formed by this enzyme. ${ }^{[58,59]}$ Similarly, the nonheme iron dioxygenase AsqJ performs two steps in the biosynthesis process of 4'-methoxyviridicatin; one involving a desaturation and the other an epoxidation reaction. ${ }^{[60]}$ Again, this is a highly selective reaction that can only be achieved through tight binding and positioning of the substrate and oxidant in the active site of the protein. Therefore, nonheme iron dioxygenases involved in natural product synthesis, antibiotics or hormone biosynthesis are highly selective and specific and have a tight substrate binding pocket to accommodate this feature. ${ }^{[61]}$

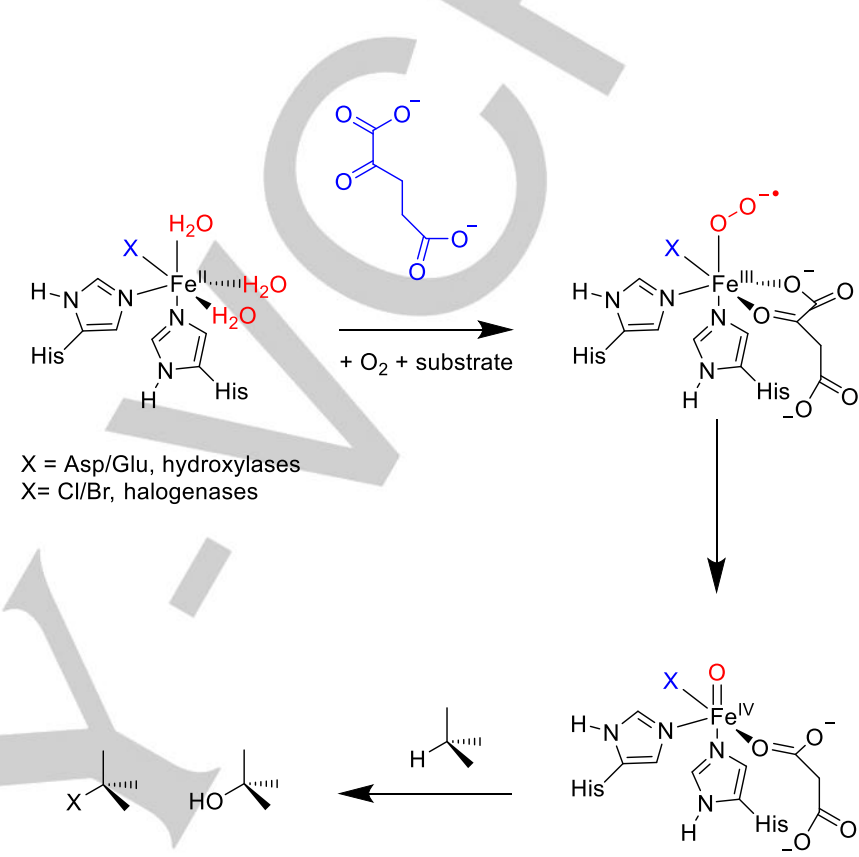

Scheme 3. General reaction mechanism of nonheme iron hydroxylases and halogenases.

A nonheme iron dioxygenase that lacks the $\alpha$-ketoglutarate cosubstrate, but contains an $\alpha$-ketoglutarate group as part of its substrate scaffold is (S)-mandelate synthase. It binds $p$ hydroxyphenylpyruvate through the $\alpha$-keto and carboxylate groups to iron and reacts directly on the iron center with dioxygen through an initial decarboxylation and the formation of an iron(IV)oxo species. ${ }^{[62]}$ In a subsequent step the substrate is hydroxylated to form (S)-mandelate enantio- and stereoselectively. Indeed a detailed product analysis showed that the system provided $>99 \%$ of the (S)-mandelate product and virtually no $(R)$-mandelate was observed. Nevertheless, Straganz et al. showed that through second-coordination sphere engineering of the protein the substrate binding position and orientation could be perturbed, which resulted in a change in the product distributions. In particular, using a triple mutation in the second-coordination sphere from the iron, the engineered protein generated $(R)$ mandelate products dominantly rather than the $(S)$-mandelate seen for the wildtype system. ${ }^{[63]}$ This was one of the first examples where engineering of a nonheme iron dioxygenase led to a complete stereoselectivity reversal. 

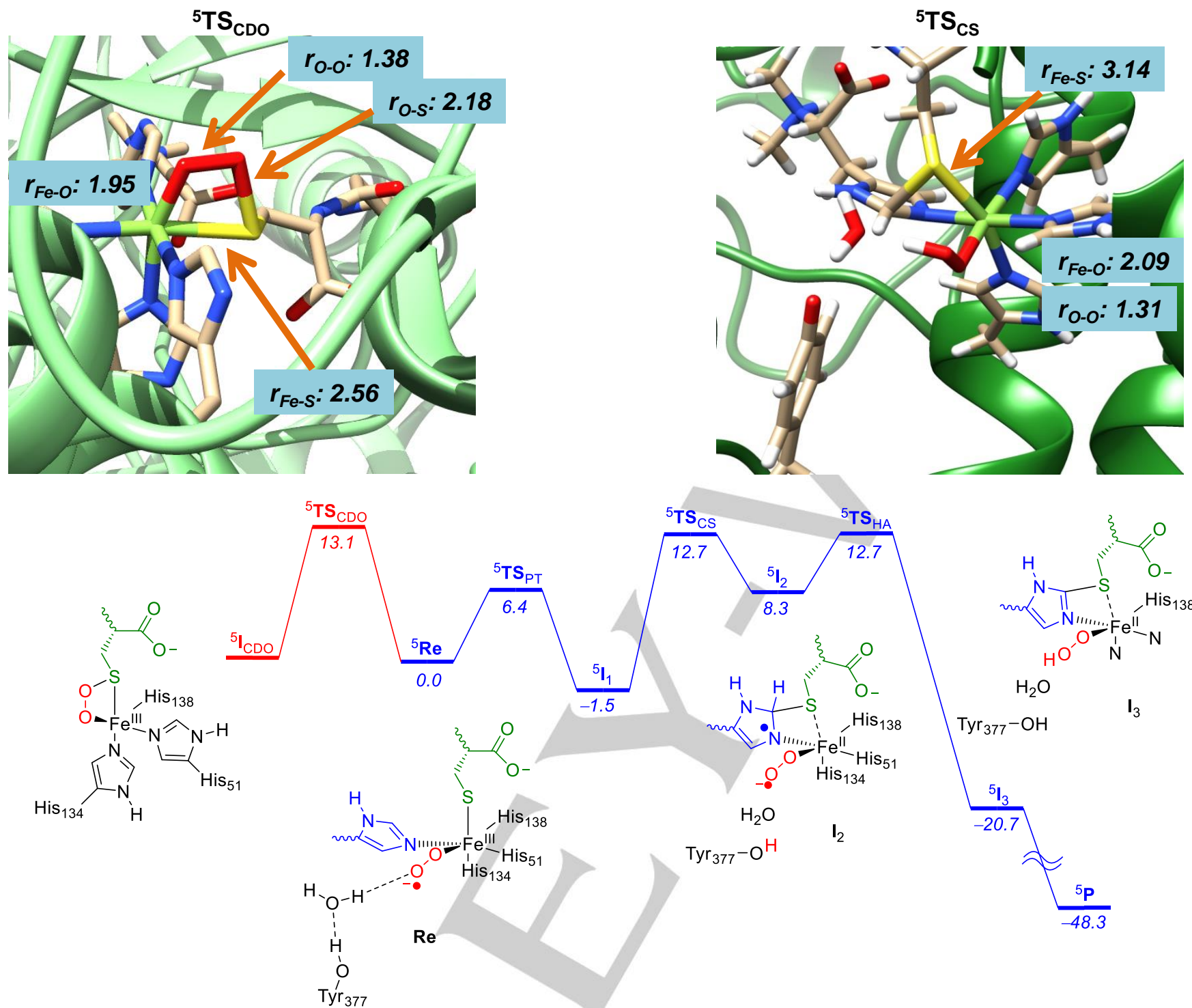

Figure 5. QM/MM calculated reaction mechanisms of EgtB activation of substrate starting from the reactant complex Re as obtained with Turbomole:Charmm Mechanism in red refers to cysteine dioxygenation pathway from an iron(III)-superoxo reactant complex, while the mechanism in blue is for sulfoxide synthase. Optimized geometries of key transition states in both pathways have bond lengths in angstroms, while the relative energies in the landscape are in $\mathrm{kcal}^{-1}$.

Another example, where the second coordination sphere is critical for the reaction mechanism and the selectivity is given in Figure 5 , where we consider cysteinate activation on a nonheme iron center by the ergiothioneine biosynthesis enzyme EgtB. ${ }^{[64]}$ This is a nonheme iron dioxygenase with a 3 -His ligand feature that binds two substrates directly to the iron center, namely $\gamma$-glutamyl cysteine $(\gamma \mathrm{GC})$ and $\mathrm{N}$ - $\alpha$-trimethyl histidine. During the biosynthesis reaction of ergothioneine a covalent linkage is created between the cysteinate group of $\gamma$-glutamyl cysteine with the histidine group of $\mathrm{N}$ - $\alpha$-trimethyl histidine. ${ }^{[65]}$ Both of these residues bind to the metal directly and react on the iron center to form a $\mathrm{C}-\mathrm{S}$ covalent bond between the two residues and in addition a thiol sulfoxidation reaction takes place presumably during the same catalytic cycle using one molecule of oxygen. Several computational studies were performed using a range of models and with small cluster models preferential initial sulfoxidation followed by $\mathrm{C}-\mathrm{S}$ bond formation was found as the lowest energy pathway. ${ }^{[64,66]}$ By contrast, a full QM/MM study that takes the protein and local environment around the iron center into consideration proposed an alternative mechanism with an initial C-S bond formation and a subsequent sulfoxidation instead. ${ }^{[64]}$ Figure 5 gives the energy landscape of oxygen activation by EgtB enzymes as calculated with QM/MM. ${ }^{[64]}$ The reaction starts from an iron(III)-superoxo reactant $\left({ }^{5} \mathbf{R e}\right)$ in a quintet spin ground state, where the iron is linked to four histidine groups (three from the protein and one from $\mathrm{N}$ - $\alpha$-trimethyl histidine substrate) and the substrate thiolate. Nearby the metal, in the second coordination sphere, is a tyrosine residue $\left(\mathrm{Tyr}_{377}\right)$ that through a network with water molecules is connected to the terminal oxygen atom of the iron(III)-superoxo group. The QM/MM studies found a major role of this Tyr residue through proton delivery as well as electron relay during the reaction. Two lowenergy competing reaction pathways were identified with $Q M / M M$, namely the attack of the superoxo on sulfur (pathway in red in Figure 5), i.e. initial sulfoxidation, and $\mathrm{C}-\mathrm{S}$ bond formation between the two substrate groups (pathway in blue), i.e. initial 
sulfide synthase pathway. The dominant and lowest energy reaction pathway for EgtB identified with $\mathrm{QM} / \mathrm{MM}$ was found to start with a low-energy proton coupled/electron transfer that initiates the sulfide synthase channel. Thus, the proton of $\mathrm{Tyr}_{377}$ is channeled through a chain of water molecules to iron(III)superoxo and simultaneously an electron is transferred from the tyrosine to iron to give an iron(II)-hydroperoxo species and a tyrosyl radical. The reduced oxidation state of the metal in the iron(II)-hydroperoxo structure leads to weakening of the Fe-S bond between iron and $\gamma \mathrm{GC}$ so that the sulfide comes off and an attack takes place on the CE1 carbon atom of the $\mathrm{N}$ - $\alpha$-trimethyl histidine group to form a $\mathrm{C}-\mathrm{S}$ linkage between the two substrates. A barrier of $12.7 \mathrm{kcal} \mathrm{mol}^{-1}$ via ${ }^{5} \mathbf{T S}_{\mathrm{cs}}$ was calculated for this process, see Figure 5. The structure has a very long Fe-S bond of $3.14 \AA$ as well as a long $\mathrm{Fe}-\mathrm{OOH}$ distance of $2.09 \AA$. Simultaneously, with the $\mathrm{C}-\mathrm{S}$ bond formation; however, the proton of the iron(II)-hydroperoxo is relayed back to the tyrosine residue. Subsequently, the iron(II)-superoxo picks up the ipsoproton from the linked substrates to form iron(II)-hydroperoxo and a crosslinked His-Cys group to form structure $\mathbf{I}_{3}$. In a final almost barrierless - process the second oxygen atom is transferred to substrate to form the sulfoxide products $(\mathbf{P})$.

An alternative suggestion of the mechanism initiating with $\mathrm{C}-\mathrm{S}$ bond formation, is the reverse pathway that starts with sulfoxidation of the thiolate substrate followed by $\mathrm{C}-\mathrm{S}$ bond formation. However, in that pathway, the sulfoxide intermediate can be further oxidized to cysteine sulfinic acid in a mechanism analogous to cysteine dioxygenase. To find out if initial oxygen atom transfer to $\gamma \mathrm{GC}$ could lead to a sulfoxide synthase reaction or would lead to cysteine sulfinic acid products in EgtB, both mechanisms were evaluated with QM/MM. For EgtB, the QM/MM studies find an initial first oxygen atom transfer from reactants (pathway in red in Figure 5) with a barrier of $13.1 \mathrm{kcal} \mathrm{mol}^{-1}$. This value matches the one found for CDO where QM/MM predicted an oxygen atom transfer barrier of $13.7 \mathrm{kcal} \mathrm{mol}^{-1}$ using the same computational methods and procedures. In the CDO calculations the mechanism was followed by several low-energy barriers for dioxygen bond cleavage and second oxygen atom transfer to form cysteine sulfinic acid products. ${ }^{[67]}$ The barrier for the first oxygen atom transfer in $\mathrm{CDO}$ is close to the one reported for EgtB (Figure 5). A similar barrier for oxygen atom transfer for EgtB and CDO implies that in both cases the second-coordination sphere effect is small and has not affected the thermodynamics and kinetics of the oxygen atom transfer reaction. However, in contrast to small model calculations, the QM/MM studies gave no low-energy pathway for the subsequent formation of a $\mathrm{C}-\mathrm{S}$ bond between cysteine-sulfoxide and the histidine substrate in EgtB; and, therefore, EgtB cannot start with an initial oxygen atom transfer to sulfide. Moreover, EgtB has a lower energy pathway than oxygen atom transfer, namely the proton-coupled/electron transfer from $\mathrm{Tyr}_{377}$ followed by $\mathrm{C}-\mathrm{S}$ bond formation between the two substrates.

Overall, the computational studies (QM/MM, DFT and MD) show that EgtB is a very rigid protein, where the flexibility is limited and the substrates are locked tightly in position due to several hydrogen bonding and salt bridge interactions in the secondcoordination sphere. As a result of that the two substrates do not have enough flexibility to reorient to the ideal position for $\mathrm{C}-\mathrm{S}$ bond formation between sulfoxide and $\mathrm{N}$ - $\alpha$-trimethyl histidine. By contrast, the $\mathrm{C}-\mathrm{S}$ bond formation between $\gamma \mathrm{GC}$ and $\mathrm{N}$ - $\alpha$-trimethyl histidine is easier as it happens close to the iron and is lesser dependent on the second-coordination sphere environment and substrate positioning. These studies show that the order of the reactions is important and guided by the positioning of the substrates in the binding pocket, their orientations and the availability of protons during the reactions.

The QM/MM calculations, therefore, show that substrate binding and positioning is important in EgtB enzymes as it brings the histidine group of $\mathrm{N}$ - $\alpha$-trimethyl histidine close to the thiolate of $\gamma$ glutamyl cysteine. Moreover, an active site tyrosine residue helps creating a viable oxidant to initiate the $\mathrm{C}-\mathrm{S}$ bond formation step by weakening the $\mathrm{Fe}-\mathrm{S}$ bond and triggering a reaction with $\mathrm{N}-\alpha-$ trimethyl histidine. Indeed, replacement of the $\mathrm{Tyr}_{377}$ residue with phenylalanine led to a dramatic drop in reactivity as compared to wildtype enzyme. ${ }^{[68]}$ In particular, dominant cysteine oxidation was observed. The calculations reported in Figure 5 support these studies and highlight an important role of the $\mathrm{Tyr}_{377}$ residue.

In the next couple of sections we will describe some more recent studies on substrate activation by nonheme iron dioxygenases and halogenases and the second-coordination sphere effects on the product distributions.

\subsection{Substrate positioning in prolyl-4-hydroxylase}

Prolyl-4-hydroxylase (P4H) is a nonheme iron dioxygenase that binds a protein chain and regio- and stereospecifically converts a proline residue in the chain to $(2 S, 4 R)$-4-hydroxyproline, which is an essential building block for the biosynthesis of collagen in the skin. ${ }^{[50,69]}$ The active species in the catalytic cycle of $\mathrm{P} 4 \mathrm{H}$ is an iron(IV)-oxo intermediate and was trapped and characterized with spectroscopic methods including UV-vis absorption, electron paramagnetic resonance and Mössbauer spectroscopy. ${ }^{[70]}$ Deuterium isotope effect labelling and kinetics showed that the rate-determining step in the mechanism is hydrogen atom abstraction from the $\mathrm{C}^{4}-\mathrm{H}$ position of proline by the iron(IV)-oxo species. ${ }^{[70]}$ Thermodynamically; however, the weakest $\mathrm{C}-\mathrm{H}$ bond of proline is at the $\mathrm{C}^{5}$ position and hence, ${ }^{[58]}$ the question is how the protein can block a low energy hydrogen atom abstraction pathway from the $\mathrm{C}^{5}-\mathrm{H}$ position and drive the reaction to thermodynamically unfavorable $\mathrm{C}^{4}$-hydroxylation pathway instead. To understand how $\mathrm{P} 4 \mathrm{H}$ avoids hydrogen atom abstraction from the $\mathrm{C}^{5}-\mathrm{H}$ position in favor of $\mathrm{C}^{4}-\mathrm{H}$ hydroxylation, a series of detailed computational studies were performed. ${ }^{[58,59]}$

Figure 6 displays the QM/MM optimized geometry of the quintet spin iron(IV)-oxo species, i.e. the active oxidant of $\mathrm{P} 4 \mathrm{H}$, with particular focus on the position of the substrate and iron(IV)-oxo species with respect to protein residues. The first-coordination sphere of ligands of the iron(IV)-oxo species are the His ${ }_{143}, \mathrm{Asp}_{145}$, $\mathrm{His}_{227}$ and succinate ligands. The substrate (a small peptide of nine residues with proline in the center) is shown as an amber surface and the close lying amino acid residues of the protein are highlighted. As can be seen, the peptide chain is positioned tightly by bulky mostly aliphatic and aromatic residues that surround the substrate binding pocket. Thus, $\mathrm{Trp}_{99}, \mathrm{Tyr}_{140}, \mathrm{Phe}_{147}$ (in grey behind the substrate in Figure 6) and $\operatorname{Trp}_{243}$ line the central proline residue that is being hydroxylated in the process. In addition, several charged residues interact with the peptide backbone of the substrate through hydrogen bonding interactions, namely the $\operatorname{Arg}_{93}$ and $\operatorname{Arg}_{161}$ residues. The last two residues that surround the central proline residue of the chain are two valine amino acid side chains $\left(\mathrm{Val}_{79}\right.$ and $\left.\mathrm{Val}_{80}\right)$. These residues tightly bind the substrate and position it into the required orientation for activation. 
The iron(IV)-oxo species is also in a tight conformation in the protein and the oxo group is seen to form hydrogen bonding interactions with the phenol group of $\mathrm{Tyr}_{140}$ directly and via a water molecule binds to the $\mathrm{NH}$ group of the indole group of $\operatorname{Trp}_{243}$. Therefore, the oxidant is tightly positioned through a hydrogen bonding network and in a rigid orientation and conformation. The positioning of the substrate and oxidant in the protein orient the $\mathrm{C}^{4}-\mathrm{H}$ group directly to the iron(IV)-oxo and enables regio- and stereoselective hydrogen atom abstraction. Indeed, the calculated hydrogen atom abstraction from this starting position is lowest in energy and hydrogen atom abstraction from the $\mathrm{C}^{5}-\mathrm{H}$ or $\mathrm{C}^{3}-\mathrm{H}$ groups are higher in energy and; therefore, are unlikely to take place in the enzyme. Moreover, a 10 ns molecular dynamics simulation was done prior to the QM/MM optimization and showed little changes in the protein structure over the period of the scan. Therefore, the oxidant and substrate are tightly bound through strong interactions with the protein that fix the structure in a compact and tight conformation.

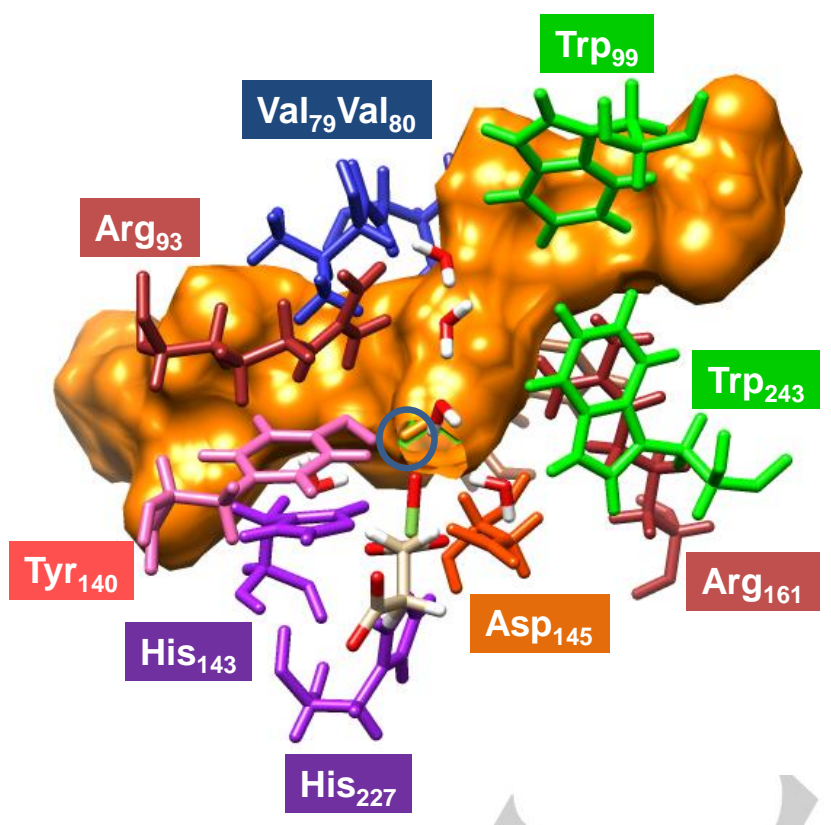

Figure 6. QM/MM optimized geometry of quintet spin iron(IV)-oxo species with small peptide chain bound. The substrate is shown as an amber surface. The atom in the blue circle is the $\mathrm{C}^{4}-\mathrm{H}$ bond of the central proline residue in the chain and is located close to the iron(IV)-oxo species: oxygen in red, iron in light green.

In addition to calculations on the wildtype reaction mechanism, QM/MM optimizations and MD simulations on several mutant structures were performed, where second-coordination sphere residues were replaced by either Gly or Phe. Thus, $\mathrm{P} 4 \mathrm{H}$ variants with either the $\mathrm{Tyr}_{140}$ or $\operatorname{Trp}_{243}$ residues replaced by Gly or Phe showed loss of selectivity and preferential $\mathrm{C}^{5}-\mathrm{H}$ hydroxylation in some cases, while in other cases complete loss of activity was observed. Interestingly, loss of activity was also found upon replacement of $\operatorname{Arg}_{161}$ by either Glu or Gly. As such, the substrate binding pocket is very tight and enables ideal interactions between substrate and oxidant that favor $\mathrm{C}^{4}-\mathrm{H}$ hydroxylation of a proline residue. Minor changes in the positioning of the substrate and addition of flexibility to the substrate and/or oxidant binding positions by active site mutations led to a loss of activity as predicted by the calculations. Therefore, the second-coordination sphere of $\mathrm{P} 4 \mathrm{H}$ plays an essential role into bringing substrate and oxidant close enough together and under the right orientation to trigger a regio- and stereospecific reaction mechanism.

Similarly to the substrate positioning in prolyl-4-hydroxylase, the flavonol biosynthesis enzyme reacts highly selectively with substrate by performing an unusual desaturation of a sixmembered ring structure. Thus, in plants flavonols are synthesized from dihydroflavonol through a desaturation reaction by a nonheme iron dioxygenase using dioxygen and $\alpha$ ketoglutarate. ${ }^{[71]}$ A recent computational study showed that, against chemical intuition, the enzyme abstracts the strongest of the two $\mathrm{C}-\mathrm{H}$ bonds of the substrate first. ${ }^{[72]}$ It was shown that substrate positioning in the active site guided the reaction to the thermodynamically less favorable pathway is important as it drives the reaction to selective desaturation, while an initial hydrogen atom abstraction from the other position would lead to dominant substrate hydroxylation instead. As such nature has a range of nonheme iron enzymes that perform negative catalysis, whereby the thermodynamically favored pathway is blocked through stereochemical interactions and substrate and oxidant positioning in the active site. ${ }^{[72]}$

\subsection{Salt bridge positioning in $\alpha$-ketoglutarate dependent hydroxylases}

Many nonheme iron hydroxylases utilize $\alpha$-ketoglutarate $(\alpha K G)$ as a co-substrate that reacts with an iron(III)-superoxo species to form a high-valent iron(IV)-oxo species and succinate. ${ }^{[73]}$ In many of these dioxygenases, the $\alpha \mathrm{KG}$ group is positioned tightly in the active site pocket and binds as a bidentate ligand to iron through its $\alpha$-keto and acid groups. The terminal carboxylate group of $\alpha \mathrm{KG}$; however, is usually part of a salt bridge with an arginine residue that positions the $\alpha \mathrm{KG}$ co-substrate in a specific orientation. In most nonheme iron/ $\alpha$-ketoglutarate dependent dioxygenases the Arg residue that locks $\alpha \mathrm{KG}$ in position is part of the same loop as the axial histidine residue and typically 11 residues separated from it, i.e. a $\mathrm{HX}_{10} \mathrm{R}$ motif is commonly seen. For example, this is indeed observed in the crystal structure coordinates of, e.g., taurine/ $\alpha$-ketoglutarate dioxygenase (TauD), $\alpha$-ketoglutarate-dependent leucine 5-hydroxylase (GriE), and 2(trimethylammonio) ethylphosphonate hydroxylase (TmpA). ${ }^{[74]}$ In the ethylene forming enzyme (EFE), interestingly, the position of this Arg residue has shifted to a closer position to the axial histidine group in the protein chain and we find a $H X_{8} R$ motif in the pdb file. ${ }^{[75]}$ In addition, the structure of EFE shows a second Arg residue in hydrogen bonding distance to the terminal carboxylate group of $\alpha K G$ in the substrate-bound pdb file, namely $\operatorname{Arg}_{171}$. As a consequence, the $\alpha K G$ in EFE appears to have an alternative position in the enzyme and different interactions with protein residues. These differences may affect its catalytic properties and reaction cycles.

To highlight the difference in the $\alpha \mathrm{KG}$ position in the protein structure of EFE as compared to alternative nonheme iron/ $\alpha \mathrm{KG}$ dependent dioxygenases, we created an overlay of the crystal structure coordinates of TauD (1OS7 pdb file) and EFE (5V2Y pdb file), see Figure $7 .{ }^{[74 a, 75]}$ Both structures have the typical 2-His/1Asp facial ligand motif and we created an overlay of these firstcoordination sphere ligands of the two proteins in roughly the same position. That means His 99 is matched to $\mathrm{His}_{189}, \mathrm{Asp}_{101}$ is 
matched to $\mathrm{Asp}_{191}$ and $\mathrm{His}_{255}$ is matched with $\mathrm{His}_{268}$. The chain numbers already show that the actual proteins are quite different in size and three dimensional structure and fold. Nevertheless, the facial 2-His/1-Asp first-coordination sphere orientation is the same for both proteins.

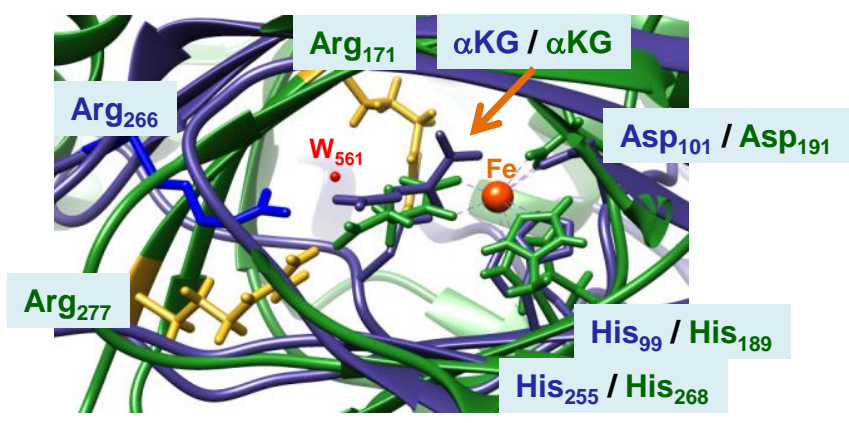

TauD / EFE

Figure 7. Overlay of the crystal structure coordinates of TauD (1OS7 pdb) and EFE (5V2Y pdb). The iron with its first-coordination sphere of ligands is shown (TauD in blue, EFE in green) and the second-coordination sphere hydrogen bonding network around $\alpha \mathrm{KG}$.

Although, $\alpha K G$ is positioned in roughly the same orientation in both TauD and EFE, actually there are clear differences in binding patterns and second-coordination sphere environment. Thus, the position of $\alpha$-ketoglutarate $(\alpha K G)$ has shifted in the EFE structure as compared to TauD. In both enzymes the $\alpha$-keto group is located trans to the carboxylate group of the Asp ligand of iron. However, the carboxylate group of $\alpha \mathrm{KG}$ is in a different location in TauD and EFE. In particular, it is trans to $\mathrm{His}_{255}$ in TauD but trans to $\mathrm{His}_{189}$ in EFE. Most likely this conformational change affects its catalytic ability and its reaction with dioxygen. Based on the crystal structure coordinates of Figure 7 it is expected that dioxygen in EFE binds trans to His ${ }_{189}$, while in TauD it most likely binds trans to $\mathrm{His}_{255}$. In addition, the carboxylate group of $\alpha \mathrm{KG}$ interacts with the $\operatorname{Arg}_{171}$ of which the side chain points into the substrate binding pocket. This residue is missing in TauD. These differences in $\alpha \mathrm{KG}$ positioning may determine the differences in reactivity of TauD versus EFE, but a detailed computational study that compares these two enzymes has not been reported yet.

A recent computational study on EFE focused on the possible reaction pathways for the conversion of $\alpha K G$ into ethylene and three molecules of $\mathrm{CO}_{2}$ and the alterative reaction mechanism for arginine hydroxylation. ${ }^{[76]}$ Thus, EFE binds a free arginine amino acid as a substrate into the binding pocket and with the help of dioxygen reacts $\alpha \mathrm{KG}$ to ethylene, although a small amount of hydroxylated arginine is also observed. ${ }^{[77]}$ Lai et al. ${ }^{[76]}$ using $\mathrm{QM} / \mathrm{MM}$ on a full enzyme model of EFE studied the full reaction mechanism for the two reaction pathways and established mechanisms leading to arginine hydroxylation and ethylene formation, and the key steps for the initial reaction steps are summarized in Scheme 4. The work started from an iron(III)superoxo intermediate with $\alpha \mathrm{KG}$ bound to iron as a bidentate ligand, while substrate arginine is nearby bound in a second substrate binding pocket. It forms a direct hydrogen bond with the carboxylate of the Asp ${ }_{191}$ residue. Their calculated quintet spin reaction pathway starts with nucleophilic attack of the superoxo on the $\alpha$-keto position of $\alpha \mathrm{KG}$ to form persuccinate and a $\mathrm{CO}_{2}$ molecule with a barrier of $11.1 \mathrm{kcal} \mathrm{mol}^{-1}$.

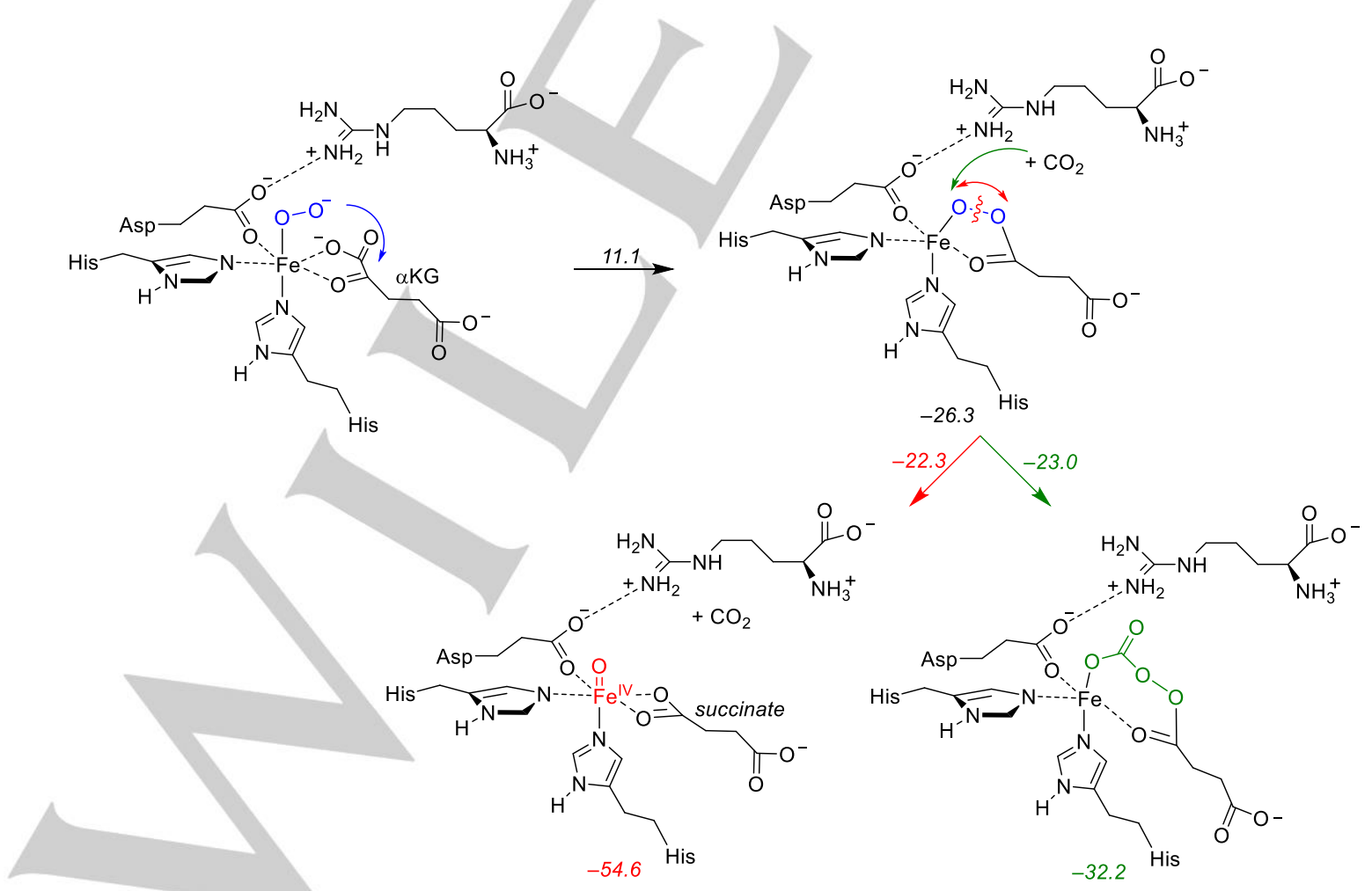

Scheme 4. QM/MM derived mechanism of competitive arginine hydroxylation (pathway in red) and ethylene formation (pathway in green) mechanisms in EFE. Energies are $\triangle \mathrm{E}+\mathrm{ZPE}$ values in $\mathrm{kcal} \mathrm{mol}^{-1}$ taken from Ref. 74 . 


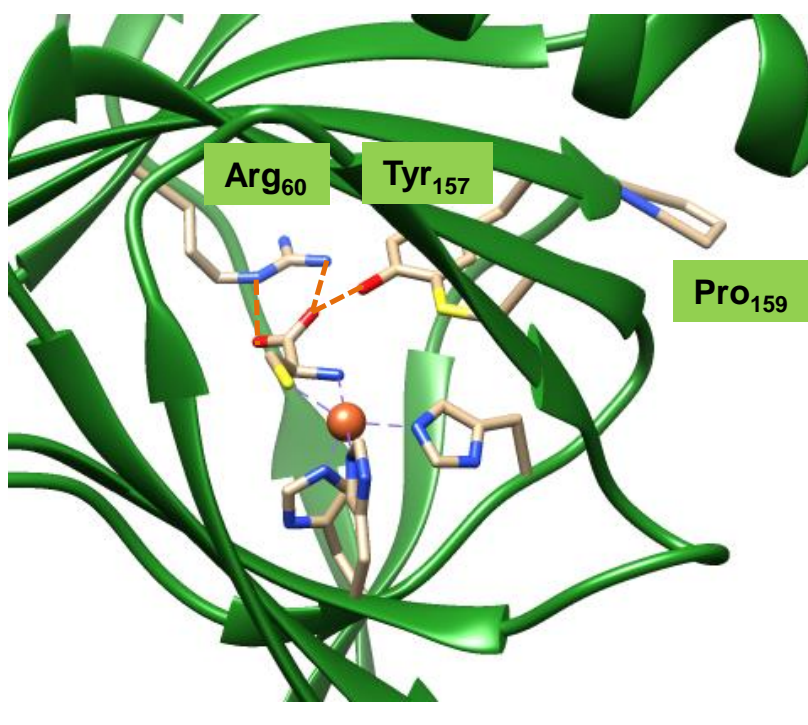

CDO: 4IEV pdb

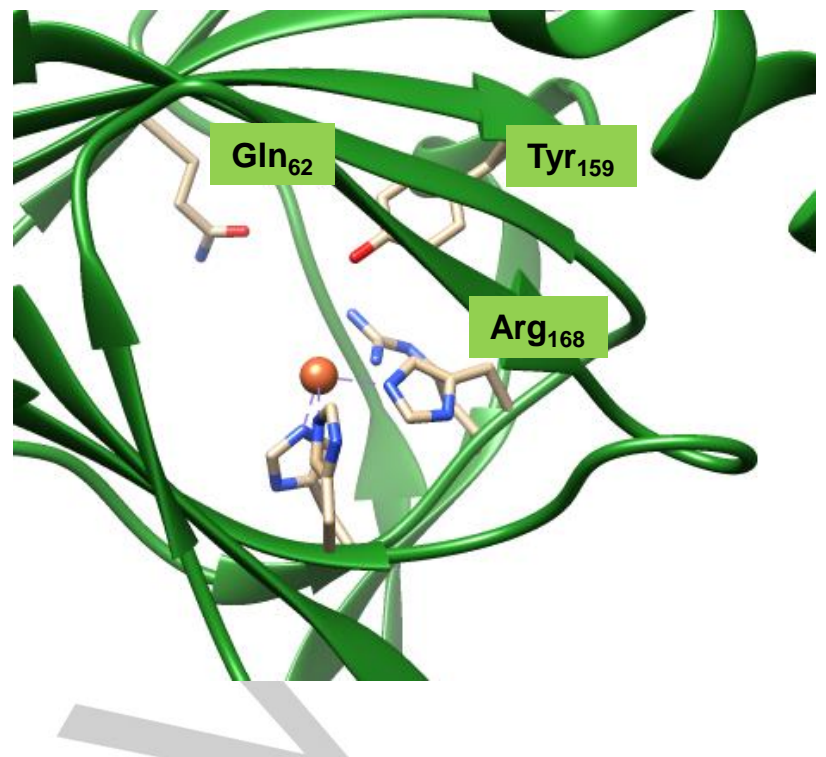

MDO: 4TLF pdb

Figure 8. Extracts of the crystal structure coordinates of $C D O$ and MDO with positioning of key salt-bridge forming residues.

This step and energetics matches previous studies on nonheme iron/ $\alpha$-ketoglutarate dependent dioxygenases excellently, ${ }^{[78]}$ and consequently, the second coordination sphere appears to have little effect on the first step in the ethylene forming enzyme, whereby $\alpha K G$ is converted into succinate and an iron(IV)-oxo species. Moreover, the structure and electronic configuration of the iron(IV)-oxo is the same as in previous computational studies of analogous systems. ${ }^{[79]}$

In the next stage the reaction bifurcates and either a homolytic cleavage of the $\mathrm{O}-\mathrm{O}$ bond occurs to form succinate and an iron(IV)-oxo species (pathway in red in Scheme 4) or alternatively $\mathrm{CO}_{2}$ attacks the terminal oxygen atom of persuccinate to form peroxic anhydride (pathway in green in Scheme 4). Thus, the iron(IV)-oxo complex was found to be a precursor to the arginine hydroxylation pathway, whereas the peroxic anhydride complex after several rearrangements forms ethylene and two $\mathrm{CO}_{2}$ molecules. The two bifurcation pathways have barriers within 1 $\mathrm{kcal} \mathrm{mol}^{-1}$ in energy. Therefore, small perturbations from the protein, such as through perturbations in the second-coordination sphere, can have a dramatic effect on the product distributions. Consequently, positioning of substrate and co-substrate, such as $\alpha K G$ or succinate is important and will drive the reaction into a favorable direction and enable a selective reaction mechanism. Another example of a nearby Arg residue in the active site that positions oxidant and substrate through a salt bridge is in the nonheme iron dioxygenase CDO. ${ }^{[51,80]}$ Interestingly, the cysteine dioxygenase does not use $\alpha$-ketoglutarate as a co-substrate but react dioxygen directly with substrate. ${ }^{[51]}$ In cysteine dioxygenase, substrate cysteine binds as a bidentate ligand to the iron and is converted into cysteine sulfinic acid efficiently. Thus, work of Jameson et al. compared the structurally and functionally similar enzymes CDO and mercaptopropionate dioxygenase (MDO). ${ }^{[80]}$ Both of these are nonheme iron enzymes that bind the metal through a 3-His coordination environment (see Figure 8). The substrate-bound pdb file (4IEV) ${ }^{[81]}$ of CDO is given on the lefthand-side of Figure 8 , while the resting state structure of MDO $(4 T L F)^{[82]}$ is given on the right. Both enzymes utilize molecular oxygen on an iron center and transfer both oxygen atoms to the sulfur atom of a substrate.

In CDO substrate cysteine binds to the iron through the thiolate and amide groups, whereas its carboxylate group forms a salt bridge with a nearby Arg residue $\left(\operatorname{Arg}_{60}\right)$. In addition, the phenol group of $\mathrm{Tyr}_{157}$ hydrogen bonds to the carboxylate as well and positions it in a tight orientation. By contrast, in MDO the Arg residue appears to be missing and the $\operatorname{Gln}_{62}$ residue occupies its position. However, MDO has an Arg residue in position 168, where CDO has a cysteine group located. Furthermore, the CDO structure has a kink in the peptide chain through a cis-Ser ${ }_{158^{-}}$ $\mathrm{PrO}_{159}$ linkage that redirects the chain, which is missing in MDO. It has been hypothesized that substrate in MDO will bind and form a salt bridge with $\operatorname{Arg}_{168}$ and hence is positioned differently from cysteine in CDO. ${ }^{[80]}$

Indeed, site-directed mutations of $\mathrm{R} 60 \mathrm{Q}$ and $\mathrm{R} 60 \mathrm{Q} / \mathrm{C} 164 \mathrm{R}$ of CDO showed a considerable drop in activity with respect to cysteine, which gives evidence of the importance of positioning the substrate in the binding pocket. In addition, a side reaction to cystine formation was observed. Therefore, the positioning of the substrate and the second-coordination sphere environment influence the reactivity and activity of proteins. 


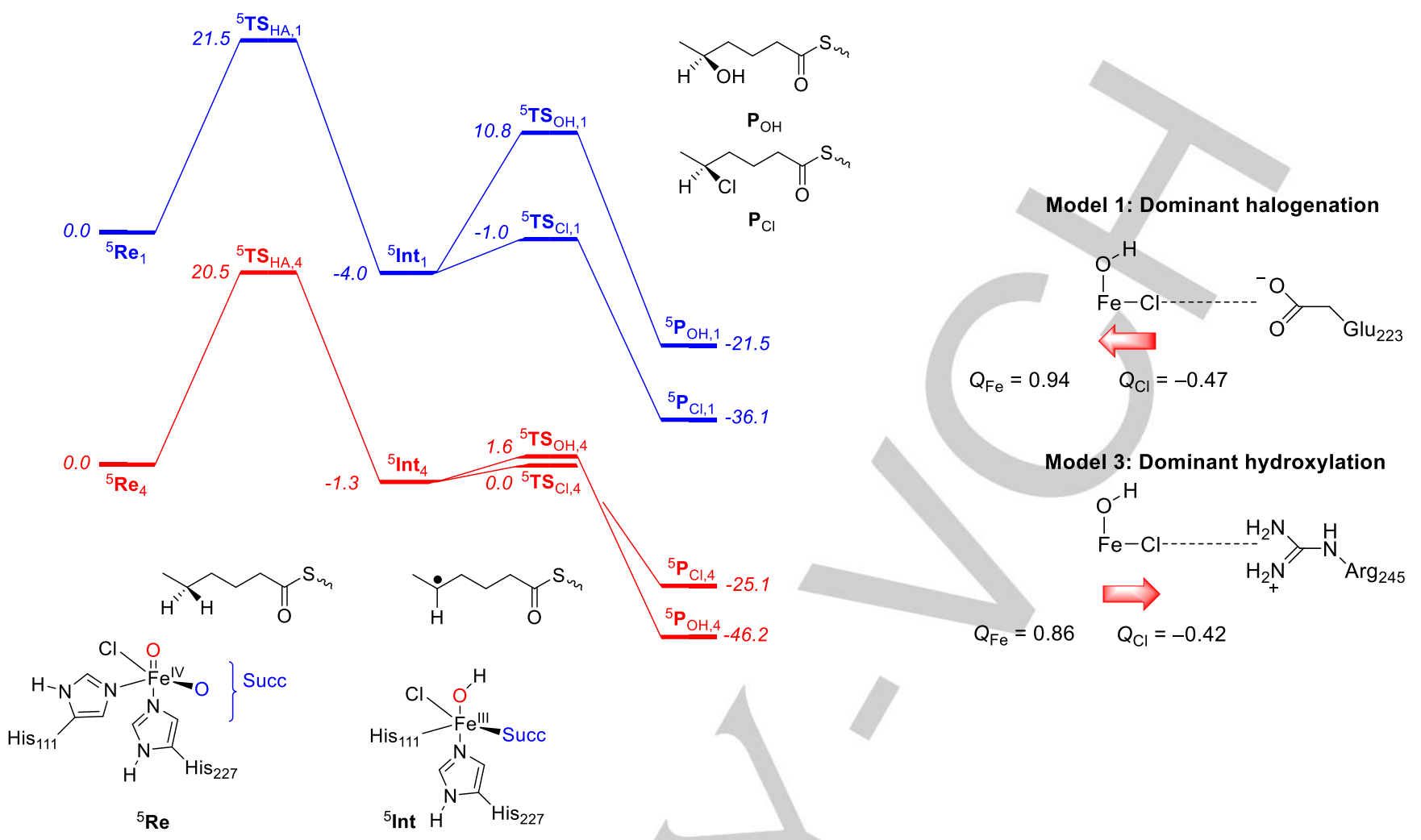

Figure 9. (a) Potential energy landscape with energies in $\mathrm{kcal}^{\mathrm{mol}}{ }^{-1}$ for substrate activation by HctB enzymes leading to hydroxylation and halogenation products as calculated with $\mathrm{QM} / \mathrm{MM}$ with the substrate in binding position 1 or 4. (b) Atomic charges of the iron(III)-hydroxo intermediates for QM/MM models with substrate in position 1 and 3. Succ stands for succinate.

\subsection{Charge stabilization in nonheme iron halogenase}

Nonheme iron halogenases activate aliphatic $\mathrm{C}-\mathrm{H}$ bonds and transfer them to $\mathrm{C}-\mathrm{Cl} / \mathrm{C}-\mathrm{Br} / \mathrm{C}-\mathrm{I}$ selectively. ${ }^{[83]}$ They generally have an active site similar to the nonheme iron/ $\alpha \mathrm{KG}$ dependent dioxygenases with the iron in a first-coordination sphere bound to two histidine ligands and an $\alpha$-ketoglutarate molecule. However, instead of the carboxylate amino acid ligand to give a facial 2His/1-Asp ligand orientation, the protein chain has a Gly residue in the Asp position that creates a small pocket that fits a halide. Consequently, the nonheme iron/ $\alpha \mathrm{KG}$ dependent halogenases have a facial 2-His/1-X ligand orientation $\left(X=\mathrm{Cl}^{-}, \mathrm{Br}^{-}\right.$or $\left.\mathrm{I}^{-}\right)$.

The nonheme iron/ $\alpha \mathrm{KG}$ dependent halogenases undergo a catalytic cycle that similarly to the $\alpha$-ketoglutarate dependent hydroxylases starts with dioxygen binding to form iron(III)superoxo and its reaction with $\alpha$-ketoglutarate to form an iron(IV)oxo species and succinate. Subsequently, the iron(IV)-oxo species is expected to react with aliphatic groups by $\mathrm{C}-\mathrm{H}$ atom abstraction as evidenced from kinetic isotope effects studies. However, instead of the normal $\mathrm{OH}$ rebound step typical for nonheme iron hydroxylases these halogenases transfer a halide atom.

How nonheme iron/ $\alpha \mathrm{KG}$ dependent halogenases avoid the $\mathrm{OH}$ rebound in favor of halide transfer has been the topic of many computational studies. ${ }^{[84]}$ Thus, calculations on small active site models of nonheme iron halogenases gave preferential hydroxylation over halogenation as expected from the more exothermic driving force of hydroxylation. ${ }^{[84]}$ Several suggestions were posed on how the hydroxylation process could be avoided, including protonation of the $\mathrm{OH}$ group by a second-coordination sphere Arg residue, ${ }^{[84 \mathrm{~b}]}$ a reaction of the iron(III)-hydroxo intermediate with $\mathrm{CO}_{2}$ to form bicarbonate, ${ }^{[84 a]}$ and hydrogen bonding interactions of the $\mathrm{OH}$ group with the alcohol group of $\mathrm{L}$ Thr. ${ }^{[84 \mathrm{c}]}$ In all of these cases, either the $\mathrm{OH}$ from the iron(III)hydroxo group was reacted away to form an unreactive water or bicarbonate molecule or alternatively it was positioned tightly through a hydrogen bonding network that prevented/slowed down the $\mathrm{OH}$ rebound process.

Recently an extensive QM/MM study was reported on the hectochlorin biosynthesis enzyme, HctB. The study came with an alternative explanation how the protein drives the reaction to substrate halogenation instead. ${ }^{[85]} \mathrm{HctB}$ is an enzyme found in Lyngbya majuscula, that halogenates an $n$-hexyl group at the $\omega-$ 1 position as a precursor step in the biosynthesis of hectochlorin. ${ }^{[86]}$ In HctB the $n$-hexyl group is tethered to an acyl carrier protein that latches onto the halogenase protein and inserts the substrate into one of the channels that reaches the active site. As there is no substrate bound crystal structure coordinate file, various substrate entrance channels were explored for HctB and substrate was docked into these channels. Two major substrate entrance channels were identified to reach the nonheme iron center of the protein and substrate was inserted in both of them and after set-up for each of the substrate-bound positions a 10 ns molecular dynamics (MD) simulation was run. In most of these channels, the MD simulations gave stable 
structures where limited flexibility and mobility were seen. However, the substrate could tightly bind in at least four different conformations, which were all sampled and subsequently studied with $\mathrm{QM} / \mathrm{MM}$. These structures are designated as models 1, 2, 3 and 4 and position the substrate in a different orientation with respect to the iron center. The QM/MM studies explored several substrate binding positions in the active site and calculations were performed for substrate hydroxylation versus halogenation processes in various low-energy spin states. In all substrate binding positions, the hydrogen atom abstraction was ratedetermining and the lowest energy spin state was the quintet spin state in agreement with experimental observation. Surprisingly the calculations predicted different product distributions based on substrate placement.

Figure 9 shows two potential energy landscapes for the activation of substrate by the iron(IV)-oxo species in two different substrate binding positions (position 1 and 4) as calculated with QM/MM. The reactions start with hydrogen atom abstraction from the substrate via transition state $\mathbf{T S}_{\mathrm{HA}}$ to form an iron(III)-hydroxo intermediate ( $\left.\mathbf{I n t}_{1}\right)$ that via bifurcation pathways can react via $\mathrm{OH}$ rebound to form alcohol products (via transition state $\mathbf{T S}_{\mathrm{OH}}$ ) or through $\mathrm{Cl}$ rebound to form halogenated products (via transition state $\mathbf{T S}_{\mathrm{CI}}$ ). Thus, for both substrate-binding positions the ratedetermining step is hydrogen atom abstraction from substrate with barriers of $\Delta \mathrm{E}=20.5$ and $21.5 \mathrm{kcal} \mathrm{mol}^{-1}$ to form an iron(III)hydroxo intermediate with radical on the substrate. In the next step, two possible pathways were explored, namely $\mathrm{Cl}$ rebound to form halogenated product $\left(\mathbf{P}_{\mathrm{Cl}}\right)$ and $\mathrm{OH}$ rebound to give the alcohol products $\left(\mathbf{P}_{\mathrm{OH}}\right)$. Surprisingly, in Model 1 the $\mathrm{OH}$ rebound is high in energy $\left(14.8 \mathrm{kcal} \mathrm{mol}^{-1}\right.$ above $\left.{ }^{5} \mathrm{Int}_{1}\right)$, which is well higher in energy than typical $\mathrm{OH}$ rebound barriers found for nonheme iron and heme hydroxylases calculated previously. ${ }^{\left[{ }^{[7]}\right.}$ Usually, $\mathrm{OH}$ rebound has a small and sometimes negligible barrier and efficiently leads to alcohol products. However, when the rebound barrier is high, the iron(III)-hydroxo radical intermediate has a finite lifetime and can undergo rearrangement leading to byproducts and isomerizations. ${ }^{[72,88]}$ In nonheme iron halogenases; therefore, the protein will need to perturb the $\mathrm{OH}$ rebound barriers and destabilize them so that they are well above the barrier for $\mathrm{Cl}$ transfer in energy.

In the mechanism calculated for $\mathrm{HctB}$ using substrate binding position 1 (Figure 9) a regio- and stereoselective halogenation process is predicted that should give halogenated products exclusively due to a much lower barrier for ${ }^{5} \mathbf{T S}_{\mathrm{Cl}, 1}$ than ${ }^{5} \mathbf{T} \mathbf{S}_{\mathrm{OH}, 1}$. By contrast, the potential energy surface calculated for substrate binding position 4 with the substrate in an alternative starting orientation and position shows major differences in energy and selectivity. Although the hydrogen atom abstraction barriers and formation of the radical intermediates ${ }^{5}$ Int are very similar for the halogenase with substrate in positions 1 and 4; in the second stage of the mechanism major divergences are found. In particular, with the substrate in position 4, the barrier for $\mathrm{OH}$ rebound is similar to the one for halide rebound, i.e. ${ }^{5} \mathbf{T S}_{\mathrm{Cl}, 4}$ is close to 0 , while ${ }^{5} \mathbf{T S}_{\mathrm{OH}, 4}$ is only $1.6 \mathrm{kcal} \mathrm{mol}^{-1}$. As the difference in energy between these two bifurcation pathways is small we expect a mixture of products with the substrate in binding position 4.

To understand the different product distributions in the various conformational structures, a detailed analysis of the structure and electronic configuration of the iron(III)-hydroxo intermediates was performed. The differences in charge (and spin) distributions on the iron and halide groups in substrate binding position 1 and 4 in $\mathrm{HctB}$ are shown on the right-hand-side of Figure 9. There appears to be a link between a large amount of radical character on the halide and the barrier height for halide transfer. Thus, with large amount of radical character on the halide, it was found to lead to dominant halogenation products, whereas low amount of radical character on the halide corresponded with dominant substrate hydroxylation reactions. In particular, an anionic halide group of the iron(III)-hydroxo intermediate showed dominant substrate hydroxylation instead. An analysis of the second-coordination sphere identified an active site Glu residue that can influence local charge and group spin densities of active site residues and specifically the iron-halide groups. Thus, with the $\mathrm{Glu}_{223}$ aligned to the $\mathrm{Fe}-\mathrm{Cl}$ bond, charge is pushed from halide to iron thereby making the halide more radical in nature, hence giving halogenation as the dominant reaction channel. On the other hand, when the carboxylate group of $\mathrm{Glu}_{223}$ points away from the halide and its position is taken in by the positively charged side chain of $\operatorname{Arg}_{245}$, the reverse effect is observed and dominant hydroxylation is seen. Therefore, the second-coordination sphere residues of nonheme iron halogenases affect the charges and electronic configuration of the active site and enable a favorable substrate halogenation reaction.

The QM/MM studies on regioselective halogenation versus hydroxylation by HctB were supported by small model complexes that included the first-coordination sphere only. In particular, when this small model complex was perturbed through either the addition of a point charge in the position of $\mathrm{Glu}_{223}$ or an electric field effect along the $\mathrm{Fe}-\mathrm{Cl}$ bond, major changes in the charge distributions were obtained and the ordering of the $\mathrm{OH}$ versus $\mathrm{Cl}$ rebound changed. Thus, a point charge of +1 at a distance of $4 \AA$ from the halide gave a charge of $Q_{\mathrm{Cl}}=-0.54$, whereas a negative charge change the charge to $Q_{\mathrm{Cl}}=-0.41$. A strong electric field along the $\mathrm{Fe}-\mathrm{Cl}$ axis had an even larger effect and led to a change of 0.30 in the charge. Therefore, small perturbations in the second-coordination sphere of charged residues of Asp, Glu, Lys and Arg residues can influence charge distributions of bifurcation pathways and direct the reaction into the desired reaction channel. It would be interesting to see if protein engineering can be done that can prove this concept experimentally.

\section{Summary and Future Outlook}

In this work, I give an overview of second-coordination sphere effects in heme and nonheme iron oxygenases and how these interactions influence and guide the reactivities of the enzymes. Thus, many reactions in heme and nonheme iron dioxygenases are selective particularly those involved in biosynthesis reactions. As most substrates have multiple sites that can be activated by an oxidant and hence, with an open substrate binding pocket the substrate can reorient in many conformations leading to a multitude of products. In biosynthesis enzymes, by contrast, a specific product is needed and often it is seen that the substrate and oxidant are positioned tightly together to enable a stereoselective or regiospecific reaction mechanism. The examples shown in this work highlight the components of the second-coordination sphere that assist and guide the reaction to this achieve the high level of specificity. These secondcoordination sphere effects range from: 
(i) Hydrogen bonding interactions of the protein with substrate, oxidant or metal-ligands.

(ii) Salt-bridges between the protein and either substrate or metalligands.

(iii) Substrate positioning by aliphatic and aromatic residues.

(iv) Charge-stabilization through long-range electrostatic interactions of cation or anion binding sites or electric field effects. Thus, hydrogen bonding interactions of polar residues with substrate and/or oxidant or one of its first-coordination sphere ligands can help with substrate and oxidant placement. For instance, arginine residues in the ethylene forming enzyme position the $\alpha$-ketoglutarate substrate in the ideal conformation. Further tightly binding of substrate in substrate binding pockets is often achieved with aromatic (Phe/Tyr/Trp) and large aliphatic (Leu/Val/lle) amino acid residues. Finally, computational modelling has shown that charged residues at distances of $10-$ $15 \AA$ from a metal center can affect redox potentials as well as $\mathrm{pK}_{\mathrm{a}}$ values of acidic and basic residues and thereby influence reactivity pathways. Particularly, electric field effects, such as due to the dipole moment of the full protein and its immediate surrounding has been shown to influence reaction barriers and bifurcation pathways.

Overall, computational modelling assists in gaining understanding of these challenging reaction processes and development is underway to engineer proteins and change chemo-, and regioselectivities of enzymes. Indeed, over the past couple of years a number of biomimetic model complexes have been reported with a second-coordination sphere. ${ }^{[89]}$ These models identified the importance of the second-coordination sphere on substrate and oxidant positioning as well as on the selectivity of the reaction.

\section{Acknowledgements}

Margriet de Visser is acknowledged for making the photos. All $\mathrm{PhD}$ and undergraduate students involved in the work discussed here are thanked.

Keywords: cytochrome P450 • nonheme iron dioxygenases • hydroxylation $\cdot$ enzyme mechanism $\cdot$ computational modelling

\section{References}

[1] a) M. Sono, M. P. Roach, E. D. Coulter, J. H. Dawson, Chem. Rev. 1996 96, 2841-2888; b) B. Meunier, S. P. de Visser, S. Shaik, Chem. Rev. 2004, 104, 3947-3980; c) I. G. Denisov, T. M. Makris, S. G. Sligar, I. Schlichting, Chem. Rev. 2005, 105, 2253-2277; d) P. R. Ortiz de Montellano (Ed.) Cytochrome P450: Structure, Mechanism and Biochemistry, Kluwer Academic/Plenum Publishers, New York, 2005, 3rd Ed; e) X. Huang, J. T. Groves, Chem. Rev. 2018, 118, 2491-2553.

[2] a) I. F. Sevrioukova, T. L. Poulos, Dalton Trans. 2013, 42, 3116-3126; b) F. P. Guengerich, Chem. Res. Toxicol. 2017, 30, 2-12.

[3] a) M. Gregory, P. J. Mak, S. G. Sligar, J. R. Kincaid, Angew. Chem. Int. Ed. 2013, 52, 5342-5345; b) F. P. Guengerich, ACS Catal. 2018, 8 , 10964-10976; c) R. Nagel, R. J. Peters, Angew. Chem. Int. Ed. 2018, 57, 6082-6085; d) G. Jiang, Y. Zhang, M. M. Powell, S. M. Hylton, N. W. Hiller, R. Loria, Y. Ding, ChemBioChem. 2019, 20, 1068-1077; e) C. T. Walsh, B. S. Moore, Angew. Chem. Int. Ed. 2019, 58, 6846-6879.

[4] a) M. A. Marletta, Cell 1994, 78, 927-930; b) C.-C. Wei, B. R. Crane, D. J. Stuehr, Chem. Rev. 2003, 103, 2365-2383.
[5] a) C. J. Schofield, Z. Zhang, Curr. Opin. Struc. Biol. 1999, 9, 722-731; b) M. Costas, M. P. Mehn, M. P. Jensen, L. Que Jr, Chem. Rev. 2004 104, 939-986; c) M. M. Abu-Omar, A. Loaiza, N. Hontzeas, Chem. Rev. 2005, 105, 2227-2252; d) S. P. de Visser, D. Kumar (Eds.) Ironcontaining enzymes: Versatile catalysts of hydroxylation reactions in nature, Royal Society of Chemistry Publishing, Cambridge (UK), 2011; e) E. I. Solomon, K. M. Light, L. V. Liu, M. Srnec, S. D. Wong, Acc. Chem. Res. 2013, 46, 2725-2739; f) J. M. Bollinger Jr, C. Krebs, Curr. Opin. Chem. Biol. 2007, 11, 151-158.

[6] a) K. Müller-Dethlefs, P. Hobza, Chem. Rev. 2000, 100, 143-167; b) K. T. Mahmudov, M. N. Kopylovich, M. F. C. Guedes da Silva, A. J. L. Pombeiro, Coord. Chem. Rev. 2017, 345, 54-72; c) H. J. Davis, R. J. Phipps, Chem. Sci. 2017, 8, 864-877; d) M. Juanes, R. T. Saragi, W. Caminati, A. Lesarri, Chem. Eur. J. 2019, 25, 11402-11411.

[7] a) W. R. Scheidt, C. A. Reed, Chem. Rev. 1981, 81, 543-555; b) J. Hohenberger, K. Ray, K. Meyer, Nat. Commun. 2012, 3, 720-723; c) S. K. Ghosh; S. P. Rath, J. Am. Chem. Soc. 2010, 132, 17983-17985; d) R. A. Baglia, J. P. T. Zaragoza, D. P. Goldberg, Chem. Rev. 2017, 117, 13320-13352.

[8] a) D. R. Nelson, Human Genomics 2009, 4, 59-65; b) T. L. Poulos, Chem. Rev. 2014, 114, 3919-3962; c) F. P. Guengerich, M. R. Waterman, M. Egli, Trends Pharmacol. Sc. 2016, 37, 625-640.

[9] a) H. Yeom, S. G. Sligar, H. Li, T. L. Poulos, A. J. Fulco, Biochemistry 1995, 34, 14733-14740; b) J. R. Cupp-Vickery, T. L. Poulos, Nat. Struct. Biol. 1995, 2,144-153.

[10] a) N. C. Veitch, A. T. Smith, Adv. Inorg. Chem. 2000, 51, 107-162; b) E. L. Raven, Nat. Prod. Rep. 2003, 20, 367-381; c) G. Smulevich, A. Feis, B. D. Howes, Acc. Chem. Res. 2005, 38, 433-440; d) T. L. Poulos, Chem. Rev. 2014, 114, 3919-3962; e) M. Zederbauer, P. G. Furtmüller, S. Brogioni, C. Jakopitsch, G. Smulevich, C. Obinger, Nat. Prod. Rep. 2007, 24, 571-584; f) M. Alfonso-Prieto, X. Biarnés, P. Vidossich, C. Rovira, J. Am. Chem. Soc. 2009, 131, 11751-11761.

[11] a) J. H. Dawson, R. H. Holm, J. R. Trudell, G. Barth, R. E. Linder, E. Bunnenberg, C. Djerassi, S. C. Tang, J. Am. Chem. Soc. 1976, 98, 3707-3709; b) T. L. Poulos, J. Biol. Inorg. Chem. 1996, 1, 356-359; c) F. Ogliaro, S. P. de Visser, S. Shaik, J. Inorg. Biochem. 2002, 91, 554567; d) K. Sengupta, S. Chatterjee, S. Samanta, S. Bandyopadhyay, A Dey, Inorg. Chem. 2013, 52, 2000-2014; e) Y. Ishimizu, Z. Ma, M. Hada, H. Fujii, J. Biol. Inorg. Chem. 2019, 24, 483-494.

[12] a) A. W. Munro, M. A. Noble, L. Robledo, S. N. Daff, S. K. Chapman, Biochemistry 2001, 20, 1956-1963; b) B. D. Fleming, Y. Tian, S. G. Bell, L.-L. Wong, V. Urlacher, H. A. O. Hill, Eur. J. Biochem. 2003, 270, 40824088; c) A. Das, Y. V. Grinkova, S. G. Sligar, J. Am. Chem. Soc. 2007, 129, 13778-13779.

[13] a) D. Kumar, S. P. de Visser, P. K. Sharma, E. Derat, S. Shaik, J. Biol. Inorg. Chem. 2005, 10, 181-189; b) D. Kumar, S. P. de Visser, P. K. Sharma, H. Hirao, S. Shaik, Biochemistry 2005, 44, 8148-8158; c) S. P. de Visser, J. Am. Chem. Soc. 2010, 132, 1087-1097; d) D. Kumar, G. N. Sastry, S. P. de Visser, Chem. Eur. J. 2011, 17, 6196-6205.

[14] F. P. Guengerich Human cytochrome P450 enzymes. In P. R. Ortiz De Montellano (Ed.) Cytochrome P450: Structure, Mechanism and Biochemistry, Kluwer Academic/Plenum Publishers, New York, 2005, 3rd Ed, Chapter 10, pp 377-530.

[15] a) T. L. Poulos, B. C. Finzel, A. J. Howard, J. Mol. Biol. 1987, 195, 687700; b) J. H. Dawson, M. Sono, Chem. Rev. 1987, 87, 1255-1276.

[16] T. J. Dolinsky, P. Czodrowski, H. Li, J. E. Nielsen, J. H. Jensen, G. Klebe, N. A. Baker, Nucl. Acids Res. 2007, 35, W522-W525.

[17] W. Yang, S. G. Bell, H. Wang, W. Zhou, N. Hoskins, A. Dale, M. Bartlam, L.-L. Wong, Z. Rao, J. Biol. Chem. 2010, 285, 27372-27384.

[18] H. M. Girvan, H. Poddar, K. J. McLean, D. R. Nelson, K. A. Hollywood, C. W. Levy, D. Leys, A. W. Munro, J. Inorg. Biochem. 2018, 188, 18-28.

[19] A. Wang, C. D. Stout, Q. Zhang, E. F. Johnson, J. Biol. Chem. 2015, 290, 5092-5104.

[20] K. E. Slessor, J. E. Stok, S. Chow, J. J. De Voss, Chem. Eur. J. 2019, 25, 4149-4155.

[21] D. Batabyal, H. Li, T. L. Poulos, Biochemistry 2013, 52, 5396-5402.

[22] P. Schiavini, K. J. Cheong, N. Moitessier, K. Auclair, ChemBioChem. 2017, 18, 248-252. 
[23] L. K. Morlock, S. Grobe, K. Balke, S. Mauersberger, D. Böttcher, U. T. Bornscheuer, ChemBioChem. 2018, 19, 1954-1958.

[24] a) Andrés Olmedo, J. C. del Río, J. Kiebist, R. Ullrich, M. Hofrichter, K. Scheibner, A. T. Martínez, A. Gutiérrez, Chem. Eur. J. 2017, 23, 1698516989; b) A. W. Munro, K. J. McLean, J. L. Grant, T. M. Makris, Biochem. Soc. Trans. 2018, 46, 183-196.

[25] M. Pickl, S. Kurakin, F. G. Cantú Reinhard, P. Schmid, A. Pöcheim, C. K. Winkler, W. Kroutil, S. P. de Visser, K. Faber, ACS Catal. 2019, 9, 565577.

[26] a) M. Sivaraja, D. B. Goodin, M. Smith, B. M. Hoffman, Science 1989 245, 738-740; b) B. M. Hoffman, Acc. Chem. Res. 2003, 36, 522-529.

[27] a) V. Fülöp, N. J. Watmough, S. J. Ferguson, Adv. Inorg. Chem. 2001, 51, 163-204; b) P. R. Ortiz de Montellano, Annu. Rev. Pharmacol. Toxicol. 1992, 32, 89-107.

[28] S. P. de Visser, J. Phys. Chem. A 2005, 109, 11050-11057.

[29] a) M. T. Green, J. Am. Chem. Soc. 1999, 121, 7939-7940; b) F. Ogliaro, S. P. de Visser, S. Cohen, P. K. Sharma, S. Shaik, J. Am. Chem. Soc 2002, 124, 2806-2817; c) T. Kamachi, Y. Shiota, T. Ohta, K. Yoshizawa Bull. Chem. Soc. Jpn. 2003, 76, 721-732; d) M. Radoń, E. Broclawik, K. Pierloot, J. Chem. Theory Comput. 2011, 7, 898-908; e) J. C. Schöneboom, H. Lin, N. Reuter, W. Thiel, S. Cohen, F. Ogliaro, S. Shaik, J. Am. Chem. Soc. 2002, 124, 8142-8151; f) C. M. Bathelt, J. Zurek, A. J. Mulholland, J. N. Harvey, J. Am. Chem. Soc. 2005, 127, 12900-12908.

[30] J. Rittle, M. T. Green, Science 2010, 330, 933-937.

[31] S. Shaik, S. P. de Visser, F. Ogliaro, H. Schwarz, D. Schröder, Curr. Opin. Chem. Biol. 2002, 6, 556-567.

[32] a) W. Nam, Acc. Chem. Res. 2007, 40, 522-531; b) Y. Watanabe, H. Nakajima, T. Ueno, Acc. Chem. Res. 2007, 40, 554-562.

[33] M. Wirstam, M. R. A. Blomberg, P. E. M. Siegbahn, J. Am. Chem. Soc. 1999, 121, 10178-10185

[34] a) H. Kuramochi, L. Noodleman, D. A. Case, J. Am. Chem. Soc. 1997 $119,11442-11451$; b) G. M. Jensen, S. W. Bunte, A. Warshel, D. B. Goodin, J. Phys. Chem. B 1998, 102, 8221-8228; c) J. N. Harvey, C. M. Bathelt, A. J. Mulholland, J. Comput. Chem. 2006, 27, 1352-1362.

[35] a) D. B. Goodin, D. E. McRee, Biochemistry 1993, 32, 3313-3324; b) J Hirst, S. K. Wilcox, J. Ai, P. Moëne-Loccoz, T. M. Loehr, D. B. Goodin, Biochemistry 2001, 40, 1274-1283.

[36] R. Singh, R. E. Berry, F. Yang, H. Zhang, F. A. Walker, A. Ivancich, Biochemistry 2010, 49, 8857-8872.

[37] a) N. Suzuki, T. Higuchi, Y. Urano, K. Kikuchi, H. Uekusa, Y. Ohashi, T. Uchida, T. Kitagawa, T. Nagano, J. Am. Chem. Soc. 1999, 121, 1157111572; b) S. Yoshioka, T. Tosha, S. Takahashi, K. Ishimori, H. Hori, I. Morishima, J. Am. Chem. Soc. 2002, 124, 14571-14579.

[38] P. J. Mak, Y. Yang, S. Im, L. A. Waskell, J. R. Kincaid, Angew. Chem. Int. Ed. 2012, 51, 10403-10407.

[39] R. Davydov, S. Im, M. Shanmugam, W. A. Gunderson, N. M. Pearl, B. M. Hoffman, L. Waskell, Biochemistry, 2016, 55, 869-883.

[40] a) F. Ogliaro, S. P. de Visser, S. Cohen, J. Kaneti, S. Shaik, ChemBioChem. 2001, 2, 848-851; b) S. P. de Visser, S. Shaik, P. K. Sharma, D. Kumar, W. Thiel, J. Am. Chem. Soc. 2003, 125, 1577915788.

[41] a) S. P. de Visser, F. Ogliaro, P. K. Sharma, S. Shaik, Angew. Chem. Int. Ed. 2002, 41, 1947-1951; Angew. Chem. 2002, 114, 2027-2031; b) S. P. de Visser, F. Ogliaro, P. K. Sharma, S. Shaik, J. Am. Chem. Soc. 2002 124, 11809-11826.

[42] J. T. Groves, G. E. Avaria-Neisser, K. M. Fish, M. Imachi, R. L. Kuczkowski, J. Am. Chem. Soc. 1986, 108, 3837-3838.

[43] R. Lonsdale, J. N. Harvey, A. J. Mulholland, J. Phys. Chem. B 2010, 114, 1156-1162.

[44] S. Shaik, S. P. de Visser, D. Kumar, J. Am. Chem. Soc. 2004, 126 $11746-11749$

[45] a) M. A. Rude, T. S. Baron, S. Brubaker, M. Alibhai, S. B. Del Cardayre, A. Schirmer, Appl. Environ. Microbiol. 2011, 77, 1718-1727; b) Y. Liu, C Wang, J. Yan, W. Zhang, W. Guan, X. Lu, S. Li, Biotechnol. Biofuels 2014, 7, 28-40; c) J. Belcher, K. J. McLean, S. Matthews, L. S. Woodward, K. Fisher, S. E. J. Rigby, D. R. Nelson, D. Potts, M. T. Baynham, D. A. Parker, D. Leys, A. W. Munro, J. Biol. Chem. 2014, 289 6535-6550; d) A. Dennig, M. Kuhn, S. Tassoti, A. Thiessenhusen, S. Gilch, T. Bülter, T. Haas, M. Hall, K. Faber, Angew. Chem. Int. Ed. 2015,
54, 8819-8822; e) J. L. Grant, C. H. Hsieh, T. M. Makris, J. Am. Chem. Soc. 2015, 137, 4940-4943; f) J. A. Amaya, C. D. Rutland, N. Leschinsky, T. M. Makris, Biochemistry 2018, 57, 344-353; f) S. Matthews, J. D. Belcher, K. L. Tee, H. M. Girvan, K. J. McLean, S. E. J. Rigby, C. W Levy, D. Leys, D. A. Parker, R. T. Blankley, A. W. Munro, J. Biol. Chem 2017, 292, 5128-5143.

[46] a) S. Shaik, D. Kumar, S. P. de Visser, A. Altun, W. Thiel, Chem. Rev. 2005, 105, 2279-2328; b) A. R. Groenhof, A. W. Ehlers, K. Lammertsma, J. Am. Chem. Soc. 2007, 129, 6204-6209; c) X. Huang, J. T. Groves, J. Biol. Inorg. Chem. 2017, 22, 185-207.

[47] A. S. Faponle, M. G. Quesne, S. P. de Visser, Chem. Eur. J. 2016, 22, 5478-5483.

[48] a) A. Eichler, Ł. Gricman, S. Herter, P. P. Kelly, N. J. Turner, J. Pleiss, S. L. Flitsch, ChemBioChem. 2016, 17, 426-432; b) P. P. Kelly, A. Eichler, S. Herter, D. C. Kranz, N. J. Turner, S. L. Flitsch, Beilstein J. Org. Chem 2015, 11, 1713-1720.

[49] a) E. I. Solomon, T. C. Brunold, M. I. Davis, J. N. Kemsley, S.-K. Lee, N Lehnert, F. Neese, A. J. Skulan, Y.-S. Yang, J. Zhou, Chem. Rev. 2000 100, 235-349; b) T. D. H. Bugg, Curr. Opin. Chem. Biol. 2001, 5, 550555; c) M. J. Ryle, R. P. Hausinger, Curr. Opin. Chem. Biol. 2002, 6 193-201; d) C. Krebs, D. G. Fujimori, C. T. Walsh, J. M. Bollinger Jr, Acc. Chem. Res. 2007, 40, 484-492; e) M. R. A. Blomberg, T. Borowski, F Himo, R.-Z. Liao, P. E. M. Siegbahn, Chem. Rev. 2014, 114, 3601-3658.

[50] a) K. Gorres, R. T. Raines, Crit. Rev. Biochem. Mol. Biol. 2010, 45, 106124; b) M. A. McDonough, V. Li, E. Flashman, R. Chowdhury, C. Mohr, B. M. Lienard, J. Zondlo, N. J. Oldham, I. J. Clifton, J. Lewis, L. A. McNeill, R. J. Kurzeja, K. S. Hewitson, E. Yang, S. Jordan, R. S. Syed, C. J. Schofield, Proc. Natl. Acad. Sci. U. S. A. 2006, 103, 9814-9819; c) S. C. Flagg, N. Giri, S. Pektas, M. J. Maroney, M. J. Knapp, Biochemistry 2012, 51, 6654-6666; d) J. A. Hangasky, E. Saban, M. J. Knapp, Biochemistry 2013, 52, 1594-1602; e) M. K. Koski, R. Hieta, M. Hirsilä, A. Rönkä, J. Myllyharju, R. K. Wierenga, J. Biol. Chem. 2009, 284, 25290-25301.

[51] a) M. H. Stipanuk, Annu. Rev. Nutr. 2004, 24, 539-577; b) G. D. Straganz, B. Nidetzky, ChemBioChem. 2006, 7, 1536-1548; c) C. A. Joseph, M. J. Maroney, Chem. Commun. 2007, 3338-3349; d) D. Buongiorno, G. D. Straganz, Coord. Chem. Rev. 2013, 257, 541-563; e) M. Fellner, E. Siakkou, A. S. Faponle, E. P. Tchesnokov, S. P. de Visser, S. M. Wilbanks, G. N. L. Jameson, J. Biol. Inorg. Chem. 2016, 21, 501-510.

[52] a) L. Que Jr, Nat. Struct. Biol. 2000, 7, 182-184; b) E. G. Kovaleva, J. D. Lipscomb, Nat. Chem. Biol. 2008, 4, 186-193; c) P. C. A. Bruijnincx, G. van Koten, R. J. M. Klein Gebbink, Chem. Soc. Rev. 2008, 37, 27162744

[53] a) T. D. H. Bugg, S. Ramaswamy, Curr. Opin. Chem. Biol. 2008, 12, 134 140; b) A. Karlsson, J. V. Parales, R. E. Parales, D. T. Gibson, H. Eklundm S. Ramaswamy, Science 2003, 299, 1039-1042; c) E. G. Kovaleva, M. B. Neibergall, S. Chakrabarty, J. D. Lipscomb, Acc. Chem Res. 2007, 40, 475-483; d) P. E. M. Siegbahn, F. Haeffner, J. Am. Chem. Soc. 2004, 126, 8919-8932.

[54] A. Miłaczewska, E. Kot, J. A. Amaya, T. M. Makris, M. Zając, J. Korecki, A. Chumakov, B. Trzewik, S. Kędracka-Krok, W. Minor, M. Chruszcz, T. Borowski, Chem. Eur. J. 2018, 24, 5225-5237.

[55] a) J. M. Bollinger Jr, J. C. Price, L. M. Hoffart, E. W. Barr, C. Krebs, Eur. J. Inorg. Chem. 2004, 4245-4254; b) H. J. Kulik, C. L. Drennan, J. Biol. Chem. 2013, 288, 1233-11241.

[56] a) J. C. Price, E. W. Barr, B. Tirupati, J. M. Bollinger Jr, C. Krebs, Biochemistry 2003, 42, 7497-7508; b) D. A. Proshlyakov, T. F. Henshaw, G. R. Monterosso, M. J. Ryle, R. P. Hausinger, J. Am. Chem. Soc. 2004, 126, 1022-1023; c) P. J. Riggs-Gelasco, J. C. Price, R. B. Guyer, J. H. Brehm, E. W. Barr, J. M. Bollinger Jr, C. Krebs, J. Am. Chem. Soc. 2004 126, 8108-8109

[57] a) M. L. Matthews, C. M. Krest, E. W. Barr, F. H. Vaillancourt, C. T. Walsh, M. T. Green, C. Krebs, J. M. Bollinger Jr, Biochemistry 2009, 48, 43314343; b) M. L. Neidig, C. D. Brown, K. M. Light, D. Galonić Fujimori, E. M. Nolan, J. C. Price, E. W. Barr, J. M. Bollinger Jr, C. Krebs, C. T. Walsh, E. I. Solomon, J. Am. Chem. Soc. 2007, 129, 14224-14231; c) D. Galonić Fujimori, E. W. Barr, M. L. Matthews, G. M. Koch, J. R. Yonce, C. T. Walsh, J. M. Bollinger Jr, C. Krebs, P. J. Riggs-Gelasco, J. Am. Chem. Soc. 2007, 129, 13408-13409. 
[58] B. Karamzadeh, D. Kumar, G. N. Sastry, S. P. de Visser, J. Phys. Chem. A 2010, 114, 13234-13243.

[59] A. Timmins, M. Saint-André, S. P. de Visser, J. Am. Chem. Soc. 2017, 139, 9855-9866.

[60] a) W.-c. Chang, J. Li, J. L. Lee, A. A. Cronican, Yi. Guo, J. Am. Chem Soc. 2013, 138, 10390-10393; b) Z. Wojdila, T. Borowski, J. Biol. Inorg. Chem. 2018, 23, 795-808

[61] See, e.g., a) W. Yan, H. Song, F. Song, Y. Guo, C.-H. Wu, A. . Her, Y $\mathrm{Pu}, \mathrm{S}$. Wang, N. Naowarojna, A. Weitz, M. P. Hendrich, C. E. Costello, L. Zhang, P. Liu, Y. J. Zhang, Nature 2015, 527, 539-544; b) V. Siitonen, B. Selvaraj, L. Niiranen, Y. Lindqvist, G. Schneider, M. Metsä-Ketelä, Proc. Natl. Acad. Sci. USA 2016, 113, 5251-5256; c) J.-L. Huang, Y. Tang, C.-P. Yu, D. Sanyal, X. Jia, X. Liu, Y. Guo, W.-c. Chang, Biochemistry 2018, 57, 1838-1841; d) C.-P. Yu, Y. Tang, L. Cha, S. Milikisiyants, T. I. Smirnova, A. I. Smirnov, Y. Guo, W.-c. Chang, J. Am. Chem. Soc. 2018, 140,15190-15193; e) C. R. Zwick III, H. Renata, J. Am. Chem. Soc. 2018, 140, 1165-1169.

[62] a) B. K. Hubbard, M. G. Thomas, C. T. Walsh, Chem. Biol. 2000, 7, $931-$ 942; b) A. Wójcik, E. Broclawik, P. E. M. Siegbahn, T. Borowski, Biochemistry 2012, 51, 9570-9580.

[63] S. M. Pratter, C. Konstantinovics, C. L. M. DiGiuro, E. Leitner, D. Kumar, S. P. de Visser, G. Grogan, G. D. Straganz, Angew. Chem. Int. Ed. 2013 52, 9677-9681; Angew. Chem. 2013, 125, 9859-9863.

[64] A. S. Faponle, F. P. Seebeck, S. P. de Visser, J. Am. Chem. Soc. 2017 139, 9259-9270.

[65] a) R. Burn, L. Misson, M. Meury, F. P. Seebeck, Angew. Chem. Int. Ed. 2017, 56, 12508-12511; b) A. R. Stampfli, K. V. Goncharenko, M. Meury B. N. Dubey, T. Schirmer, F. P. Seebeck, J. Am. Chem. Soc. 2019, 141, 5275-5285.

[66] a) E. A. C. Bushell, G. B. Fortowsky, J. W. Gauld, Inorg. Chem. 2012, 51, 13351-13356; b) W.-J. Wei, P. E. M. Siegbahn, R.-Z. Liao, Inorg. Chem. 2017, 56, 3589-3599.

[67] a) S. Aluri, S. P. de Visser, J. Am. Chem. Soc. 2007, 129, 14846-14847; b) D. Kumar, W. Thiel, S. P. de Visser, J. Am. Chem. Soc. 2011, 133, 3869-3882.

[68] K. V. Goncharenko, A. Vit, W. Blankenfeldt, F. P. Seebeck, Angew. Chem., Int. Ed. 2015, 54, 2821-2824.

[69] a) R. K. Bruick, S. L. McKnight, Science 2001, 294, 1337-1340; b) A. Seifert, D. M. Katschinski, S. Tonack, B. Fischer, A. N. Santos, Chem. Res. Toxicol. 2008, 21, 341-348; c) S. P. de Visser, Chem. Record 2018 18, 1501-1516; d) M. I. Abboud, R. Chowdhury, I. K. H. Leung, K. Lippl, C. Loenarz, T. D. W. Claridge, C. J. Schofield, ChemBioChem. 2018, 19 2262-2267; e) M. I. Abboud, T. E. McAllister, I. K. H. Leung, R. Chowdhury, C. Jorgensen, C. Domene, J. Mecinović, K. Lippl, R. L. Hancock, R. J. Hopkinson, A. Kawamura, T. D. W. Claridge, C. J. Schofield, Chem. Commun. 2018, 54, 3130-3133; f) H. van der Wel, J. M. Johnson, Y. Xu, C. V. Karunaratne, K. D. Wilson, Y. Vohra, G.-J. Boons, C. M. Taylor, B. Bendiak, C. M. West, Biochemistry 2011, 50 1700-1713.

[70] L. M. Hoffart, E. W. Barr, R. B. Guyer, J. M. Bollinger Jr, C. Krebs, Proc. Natl. Acad. Sci. USA 2006, 103, 14738-14743.

[71] a) M. D. White, E. Flashman, Curr. Opin. Chem. Biol. 2016, 31, 126-135; b) R. W. D. Welford, I. J. Clifton, J. J. Turnbull, S. C. Wilson, C. J. Schofield, Org. Biomol. Chem. 2005, 3, 3117-3126.

[72] S. Ghafoor, A. Mansha, S. P. de Visser, J. Am. Chem. Soc. 2019, accepted for publication.

[73] a) S. C. Trewick, T. F. Henshaw, R. P. Hausinger, T. Lindahl, B. Sedgwick, Nature 2002, 419, 174-178; b) P. Ø. Falnes, R. F. Johansen, E. Seeberg, Nature 2002, 419, 178-182; c) P. J. O'Brien, Chem. Rev. 2006, 106, 720-752; d) C. Yi, C. G. Yang, C. He, Acc. Chem. Res. 2009 $42,519-529$.

[74] a) J. R. O'Brien, D. J. Schuller, V. S. Yang, B. D. Dillard, W. N. Lanzilotta, Biochemistry 2003, 42, 5547-5554; b) P. Lukat, Y. Katsuyama, S. Wenzel, T. Binz, C. König, W. Blankenfeldt, M. Brönstrupe, R. Müller, Chem. Sci. 2017, 8, 7521-7527; c) L. J. Rajakovich, M.-E. Pandelia, A. J. Mitchell, W.-c. Chang, B. Zhang, A. K. Boal, C. Krebs, J. M. Bollinger Jr, Biochemistry 2019, 58, 1627-1647.

[75] S. Martinez, M. Fellner, C. Q. Herr, A. Ritchie, J. Hu, R. P. Hausinger, J. Am. Chem. Soc. 2017, 139, 11980-11988.
[76] J. Xue, J. Lu, W. Lai, Phys. Chem. Chem. Phys. 2019, 21, 9957-9968.

[77] a) S. Martinez, R. P. Hausinger, Biochemistry 2016, 55, 5989-5999; b) C. Eckert, W. Xu, W. Xiong, S. Lynch, J. Ungerer, L. Tao, R. Gill, P.-C. Maness, J. Yu, Biotechnol. Biofuels 2014, 7, 33-45; c) Z. Zhang, T. J. Smart, H. Choi, F. Hardy, C. T. Lohans, M. I. Abboud, M. S. W. Richardson, R. S. Paton, M. A. McDonough, C. J. Schofield, Proc. Natl. Acad. Sci. USA 2017, 114, 4667-4672.

[78] a) T. Borowski, A. Bassan, P. E. M. Siegbahn, Chem. Eur. J. 2004, 10, 1031-1041; b) S. P. de Visser, Chem. Commun. 2007, 171-173; c) A. V. Nemukhin, I. A. Topol, R. E. Cachau, S. K. Burt, Theor. Chem. Acc. 2006 115, 348-353; d) G. Cicero, C. Carbonera, K. Valegård, J. Hajdu, I. Andersson, G. Ranghino, Int. J. Quant. Chem. 2007, 107, 1514-1522; e M. G. Quesne, R. Latifi, L. E. Gonzalez-Ovalle, D. Kumar, S. P. de Visser, Chem. Eur. J. 2014, 20, 435-446; f) N. Zeb, M. H. Rashid, M. Q. E. Mubarak, S. Ghafoor, S. P. de Visser, J. Inorg. Biochem. 2019, 198, 110728.

[79] a) S. P. de Visser, Angew. Chem. Int. Ed. 2006, 45, 1790-1793; Angew. Chem. 2006, 118, 1822-1825; b) S. P. de Visser, J. Am. Chem. Soc 2006, 128, 9813-9824; c) S. Sinnecker, N. Svensen, E. W. Barr, S. Ye J. M. Bollinger Jr, F. Neese, C. Krebs, J. Am. Chem. Soc. 2007, 129, 6168-6179; d) E. Godfrey, C. S. Porro, S. P. de Visser, J. Phys. Chem A 2008, 112, 2464-2468; e) R. Latifi, M. Bagherzadeh, S. P. de Visser, Chem. Eur. J. 2009, 15, 6651-6662; f) H. Chen, W. Lai, J. Yao, S. Shaik, J. Chem. Theory Comput. 2011, 7, 3049-3053; g) E. A. C. Bushnell, G. B. Fortowsky, J. W. Gauld, Inorg. Chem. 2012, 51, 13351-13356; h) A Wójcik, M. Radoń, T. Borowski, J. Phys. Chem. A 2016, 120, 1261-1274 i) B. K. Mai, Y. Kim, Inorg. Chem. 2016, 55, 3844-3852; j) A. Ansari, A. Kaushik, G. Rajaraman, J. Am. Chem. Soc. 2013, 135, 4235-4249.

[80] S. Aloi, C. G. Davies, P. A. Karplus, S. M. Wilbanks, G. N. L. Jameson, Biochemistry 2019, 58, 2398-2407.

[81] C. M. Driggers, R. B. Cooley, B. Sankaran, L. L. Hirschberger, M. H. Stipanuk, P. A. Karplus, J. Mol. Biol. 2013, 425, 3121-3136.

[82] E. P. Tchesnokov, M. Fellner, E. Siakkou, T. Kleffmann, L. W. Martin, S. Aloi, I. L. Lamont, S. M. Wilbanks, G. N. L. Jameson, J. Biol. Chem. 2015 , 290, 24424-24437.

[83] a) A. Butler, M. Sandy, Nature 2009, 460, 848-854; b) K.-H. van Pee, C. Dong, S. Flecks, J. Naismith, E. P. Patallo, T. Wage, Adv. Appl. Microbiol. 2006, 59, 127-157; c) F. H. Vaillancourt, E. Yeh, D. A. Vosburg, S. Garneaur-Tsodikova, C. T. Walsh, Chem. Rev. 2006, 106, 3364-3378 d) J. Lantham, E. Brandenburger, S. A. Shepherd, B. R. K. Menon, J. Micklefield, Chem. Rev. 2017, 111, 232-269; e) A. Timmins S. P. de Visser, Catalysts 2018, 8, 314, doi:10.3390/catal8080314.

[84] a) S. P. de Visser, R. Latifi, J. Phys. Chem. B 2009, 113, 12-14; b) S Pandian, M. A. Vincent, I. H. Hillier, N. A. Burton, Dalton Trans. 2009, 6201-6207; c) H. J. Kulik, L. C. Blasiak, N. Marzari, C. L. Drennan, J. Am. Chem. Soc. 2009, 131, 14426-14433; d) T. Borowski, H. Noack, M. Radoń, K. Zych, P. E. M. Siegbahn, J. Am. Chem. Soc. 2010, 132, 12887-12898; e) J. Huang, C. Li, B. Wang, D. A. Sharon, W. Wu, S Shaik, ACS Catal. 2016, 6, 2694-2704.

[85] A. Timmins, N. J. Fowler, J. Warwicker, G. D. Straganz, S. P. de Visser, Front. Chem. 2018, 6, 513, doi: 10.3389/fchem.2018.00513.

[86] a) A. V. Ramaswamy, C. M. Sorrels, W. H. Gerwick, J. Nat. Prod. 2007 70, 1977-1986; b) S. M. Pratter, J. Ivkovic, R. Birner-Gruenberger, R Breinbauer, K. Zangger, G. D. Straganz, ChemBioChem. 2014, 15, 567574; c) S. M. Pratter, K. M. Light, E. I. Solomon, G. D. Straganz, J. Am. Chem. Soc. 2014, 136, 9385-9395.

[87] a) S. Shaik, S. Cohen, S. P. de Visser, P. K. Sharma, D. Kumar, S. Kozuch, F. Ogliaro, D. Danovich, Eur. J. Inorg. Chem. 2004, 207-226; b) S. Shaik, D. Kumar, S. P. de Visser, J. Am. Chem. Soc. 2008, 130, 10128-10140; c) X.-X. Li, V. Postils, W. Sun, A. S. Faponle, M. Solà, Y. Wang, W. Nam, S. P. de Visser, Chem. Eur. J. 2017, 23, 6406-6418.

[88] a) D. Kumar, L. Tahsini, S. P. de Visser, H. Yeon Kang, S. J. Kim, W. Nam, J. Phys. Chem. A 2009, 113, 11713-11722; b) M. G. Quesne, S. P. de Visser, J. Biol. Inorg. Chem. 2012, 17, 841-852; c) L. Ji, A. S. Faponle, M. G. Quesne, M. A. Sainna, J. Zhang, A. Franke, D. Kumar, R. van Eldik, W. Liu, S. P. de Visser, Chem. Eur. J. 2015, 21, 9083-9092.

[89] a) S. Sahu, L. R. Widger, M. G. Quesne, S. P. de Visser, H. Matsumura, P. Moënne-Loccoz, M. A. Siegler, D. P. Goldberg, J. Am. Chem. Soc 2013, 135, 10590-10593; b) E. A. Hill, A. C. Weitz, E. Onderko, A 
Romero-Rivera, Y. Guo, M. Swart, E. L. Bominaar, M. T. Green, M. P. Hendrich, D. C. Lacy, A. S. Borovik, J. Am. Chem. Soc. 2016, 138, 13143-13146; C) T. M. Pangia, V. Yadav, E. F. Gérard, Y.-T. Lin, S. P. de Visser, G. N. L. Jameson, D. P. Goldberg, Inorg. Chem. 2019, 58 9557-9561; d) M. Q. E. Mubarak, S. P. de Visser, Inorg. Chem. 2019 $58,15741-15750$. 


\section{Entry for the Table of Contents}

\section{Layout 1:}

\section{REVIEW}

Metalloenzymes have important functions in chemical biology and oxygen activating ones participate in biosynthesis and biodegradation reactions in biosystems. Often these reactions are stereospecific or regioselective due the specific long- or midrange interactions from the second-coordination sphere. In this review paper an overview is given of the types of second-coordination sphere effects in iron containing enzymes.

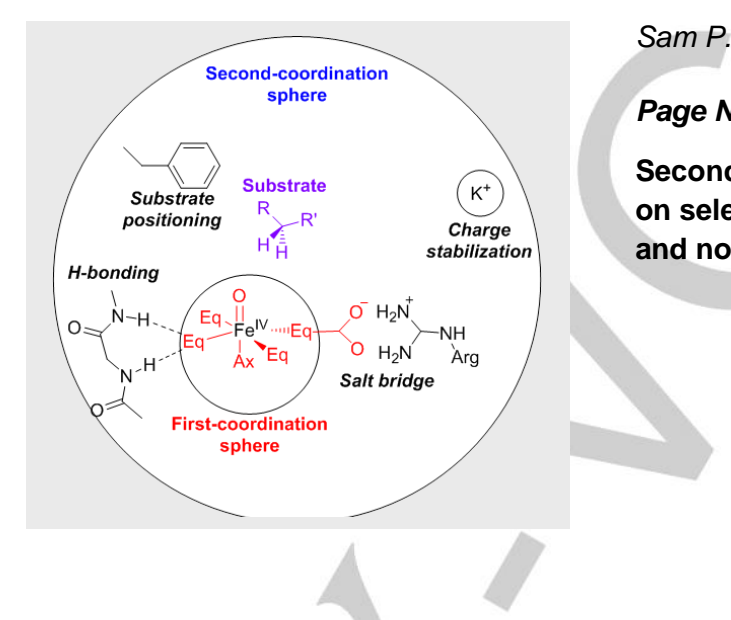

Sam P. de Visser

Page No. - Page No.

Second-coordination sphere effects on selectivity and specificity of heme and nonheme iron enzymes

Frontipiece accompanying text: (500 characters): Second-coordination sphere effects can have varying roles in enzymatic reaction mechanisms. In this review, based on extensive computational studies on heme and nonheme iron dioxygenases, several main second-coordination sphere effects are identified that determine substrate activation and product distributions. These range from substrate and oxidant positioning to hydrogen-bonding interactions and salt-bridges from the local environment. Finally, local charge and spin distributions can be affected by point charges or an applied electric field. 